\title{
Downscaling of air pollutants in Europe using uEMEP_v6
}

\author{
Qing Mu, Bruce Rolstad Denby, Eivind Grøtting Wærsted, and Hilde Fagerli \\ The Norwegian Meteorological Institute, Henrik Mohns Plass 1, 0313, Oslo, Norway \\ Correspondence: Qing Mu (qingm@met.no)
}

Received: 14 June 2021 - Discussion started: 23 July 2021

Revised: 16 November 2021 - Accepted: 6 December 2021 - Published: 19 January 2022

\begin{abstract}
The air quality downscaling model uEMEP and its combination with the EMEP MSC-W chemical transport model are used here to achieve high-resolution air quality modelling at street level in Europe. By using publicly available proxy data, this uEMEP-EMEP modelling system is applied to calculate annual mean $\mathrm{NO}_{2}, \mathrm{PM}_{2.5}, \mathrm{PM}_{10}$, and $\mathrm{O}_{3}$ concentrations for all of Europe down to $100 \mathrm{~m}$ resolution and is validated against all available AIRBASE monitoring stations in Europe at $25 \mathrm{~m}$ resolution. Downscaling is carried out on annual mean concentrations, requiring special attention to non-linear processes, such as $\mathrm{NO}_{2}$ chemistry for which frequency distributions are applied to better represent the non-linear $\mathrm{NO}_{2}$ chemistry. The downscaling shows significant improvement in $\mathrm{NO}_{2}$ concentrations for which the spatial correlation has been doubled for most countries and bias reduced from $-46 \%$ to $-18 \%$ for all stations in Europe. The downscaling of $\mathrm{PM}_{2.5}$ and $\mathrm{PM}_{10}$ does not show improvement in spatial correlation but does reduce the overall bias in the European calculations from $-21 \%$ to $-11 \%$ and from $-39 \%$ to $-30 \%$ for $\mathrm{PM}_{2.5}$ and $\mathrm{PM}_{10}$, respectively. There is improved spatial correlation in most countries after downscaling of $\mathrm{O}_{3}$ and a reduced positive bias of $\mathrm{O}_{3}$ concentrations from $+16 \%$ to $+11 \%$. Sensitivity tests in Norway show that improvements in the emission and emission proxy data used for the downscaling can significantly improve both the $\mathrm{NO}_{2}$ and $\mathrm{PM}$ results. The downscaling development opens the way for improved exposure estimates, improved assessment of emissions, and detailed calculations of source contributions to exceedances in a consistent way for all of Europe at high resolution.
\end{abstract}

\section{Introduction}

The EMEP Meteorological Synthesizing Centre - West (EMEP MSC-W) at the Norwegian Meteorological Institute has been developing and implementing a downscaling methodology to enhance the capabilities of the EMEP MSCW chemical transport model (Simpson et al., 2012, 2020) (hereafter the EMEP model). This downscaling model is known as uEMEP (urban EMEP) and can achieve highresolution air quality modelling down to $100 \mathrm{~m}$ for entire countries (Denby et al., 2020). Even though the methodology is referred to as "downscaling", uEMEP is actually an independent Gaussian plume modelling system which is added as post-processing to the EMEP model. This makes the modelling similar to other local-scale air quality models and allows for a good physical representation of air quality concentrations.

The uEMEP was first reported in the 2016 EMEP status report (Denby and Wind, 2016). Since then uEMEP has been further developed and operationally implemented in the Norwegian Air Quality Forecasting System (Miljodirektoratet, 2020 b) as well as providing air quality data, maps, and information to Norwegian municipalities through the Air Quality Expert Service (Miljodirektoratet, 2020a). These model applications and validations are described in detail in Denby et al. (2020).

The long-term aim of the uEMEP-EMEP modelling system is to extend uEMEP to cover all of the EMEP model domain so that we can have air quality modelling at street level over all of Europe. Modelling at high resolution provides a better assessment of air quality mitigation strategies in $\mathrm{Eu}-$ rope, as well as improved population exposure estimates for use in health impact studies. Previous air quality modelling across Europe could not reach such a high resolution of $100 \mathrm{~m}$ (Sofiev et al., 2015; Menut et al., 2013), or the street- 
level air quality modelling studies were limited to individual cities (Stocker et al., 2012; Kim et al., 2018). The uEMEPEMEP modelling system is now established in Norway, where access to good-quality emission related data is available. The Norwegian emissions are summarised in Sect. 5.4, and details can be found in Sect. S4.2 of Denby et al. (2020). Unfortunately, the same quality of high-resolution emission data that is available in Norway is not directly available for all of Europe. Many countries have suitable high-resolution data, but these are not readily accessible for use. In order to implement uEMEP for all of Europe proxy data that can be used to redistribute emissions to fine scales are required. Three datasets are available for all of Europe, as well as globally, and have been used to enable high-resolution modelling in Europe: OpenStreetMap (OSM) (OpenStreetMap contributors, 2020) for redistributing road traffic emissions, population data from Global Human Settlement (GHS) (Schiavina et al., 2019) gridded to $0.0025^{\circ}$ for redistributing residential heating emissions, and Automatic Identification System (AIS) (Kystverket, 2020) data for shipping emissions gridded to $0.0025^{\circ}$. These datasets allow downscaling of the traffic, residential heating, and shipping emission sources. All other sources are not included in the downscaling.

Results of the European modelling for $\mathrm{NO}_{2}, \mathrm{PM}_{2.5}, \mathrm{PM}_{10}$, and $\mathrm{O}_{3}$ are presented as example maps in Sect. 3, validation against AIRBASE stations is in Sect. 4, and results of a number of sensitivity studies are reported in Sect. 5 .

\section{Methodology}

Downscaling with uEMEP applies the following methodology with the steps illustrated in Fig. 1 and additional details in Sect. 2.1 to 2.4 .

- Calculations are made using the EMEP model for all of Europe in a way similar to the official EMEP model calculations but with the additional output of the EMEP local fractions (EMEP Status Report 1/2017, 2017; Wind et al., 2020).

- uEMEP is implemented as a post-processing routine to the annual mean output from the EMEP model. EMEP emission grids per sector and per compound are redistributed onto high-resolution sub-grids using the emission proxies.

- uEMEP then calculates the local dispersion from these sub-grid emissions using a dispersion kernel within a moving window region defined to be the size of $2 \times 2$ EMEP grids.

- uEMEP removes the local fraction contribution from the EMEP grid, within the same moving window region, and replaces these with the uEMEP sub-grid results.
- A frequency-distribution-based chemistry scheme is applied to calculate downscaled $\mathrm{NO}_{2}$ and $\mathrm{O}_{3}$ concentrations from annual mean $\mathrm{NO}_{x}\left(\mathrm{NO}+\mathrm{NO}_{2}\right)$ and $\mathrm{O}_{x}$ $\left(\mathrm{O}_{3}+\mathrm{NO}_{2}\right)$ concentrations.

- Resolution of the sub-grids varies according to the application, but maps are made at $100 \mathrm{~m}$ and calculations at monitoring sites are made at $25 \mathrm{~m}$.

\subsection{EMEP model implementation}

The EMEP model setup follows that in EMEP/MSC-W et al. (2020). Model version rv4.36 is used in this study, with a horizontal resolution of $0.1^{\circ} \times 0.1^{\circ}$ and 20 vertical layers (the lowest layer height of approximately $50 \mathrm{~m}$ ). The model domain covers the geographic area between $30-82^{\circ} \mathrm{N}$ latitude and $30^{\circ} \mathrm{W}-90^{\circ} \mathrm{E}$ longitude. The simulation year is 2018 .

The meteorological data are taken from the Integrated Forecast System (IFS) of the European Centre for MediumRange Weather Forecasts (ECMWF), with the version IFS Cycle 40r1 (ECMWF-IFS cy40r1). The emission inventory for 2018 is based on the official data submissions to the EMEP Centre on Emission Inventories and Projections (Pinterits et al., 2020) in 2020, in which the PM emissions from the residential combustion sector (GNFR C) are replaced by a bottom-up estimate of the Netherlands Organisation for Applied Scientific Research (TNO) (Denier van der Gon et al., 2020; Fagerli et al., 2020) for 2017. This TNO dataset should represent an improved estimate of residential combustion emissions of PM, accounting for condensable organics in a consistent way.

The EMEP model calculates and outputs the "local fraction" used by the uEMEP downscaling to remove double counting of emissions (Denby et al., 2020; Wind et al., 2020). The local fraction is the contribution of emissions in one EMEP grid to itself and to its neighbouring grids. For this application only a $3 \times 3$ grid contribution region is calculated, though for other applications this can be much larger. By tagging the grid emissions in this way the local contribution from EMEP can be removed and replaced by the highresolution uEMEP sub-grid calculation.

\section{2 uEMEP model implementation}

The uEMEP model is described in a recent publication (Denby et al., 2020). In that article the Norwegian forecast application of uEMEP is described, with hourly downscaling using bottom-up emission inventories carried out. For the European application calculations are made on annual mean data, creating air quality maps for Europe down to $100 \mathrm{~m}$ resolution and calculating concentrations at AIRBASE station positions down to $25 \mathrm{~m}$.

Downscaling is carried out in the following way. EMEP grid emissions per sector and per source are redistributed to uEMEP sub-grids using the proxy emission data described 


\section{Schematic outline of the UEMEP-EMEP methodology}

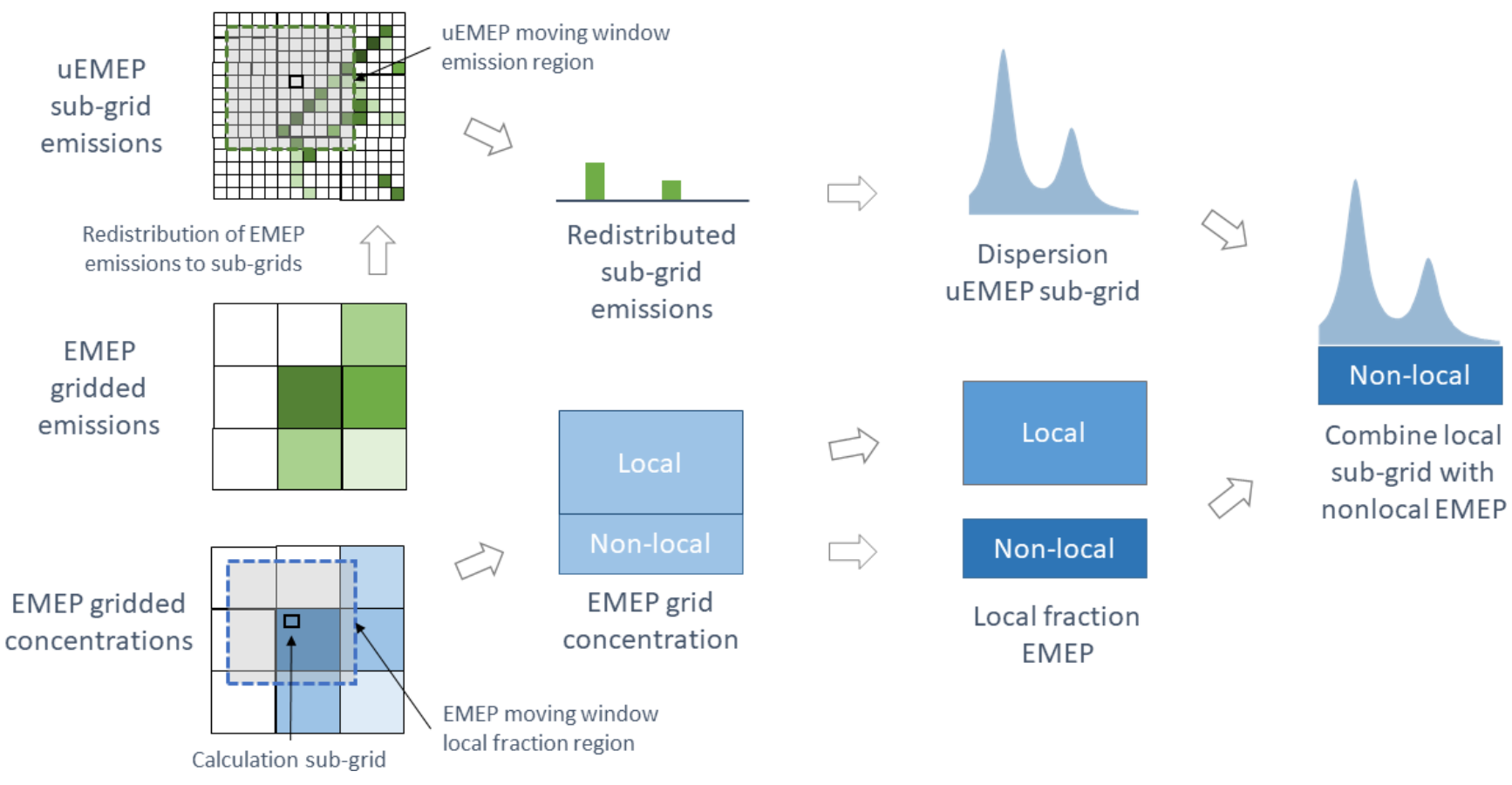

Figure 1. Schematic illustration of the uEMEP-EMEP coupled modelling system.

in Sect. 2.3. Each sub-grid dispersion calculation uses only the emission sub-grids within the moving window emission region (Fig. 1). For annual mean calculations dispersion is carried out using a rotationally symmetric Gaussian dispersion kernel (Denby et al., 2020), given an initial plume size and height. These parameters are provided in Table 1. The initial horizontal plume size is determined by the size of the sub-grid. The Gaussian dispersion parameters used are based on the $K_{z}$ dispersion methodology described in Denby et al. (2020) but adapted to the rotationally symmetric dispersion kernel. The EMEP model local fraction contribution originating from within the moving window region is removed and replaced with the sub-grid dispersion calculation from $\mathrm{uE}$ MEP, thus avoiding double counting of emissions (Fig. 1). For these simulations this region corresponds to $2 \times 2$ EMEP grids, i.e. within an area that is $\pm 0.1^{\circ}$ in both latitude and longitude. This ensures that no matter where the uEMEP calculation sub-grid is placed the moving window region will always be covered by the $3 \times 3$ local fraction region.

Downscaling with uEMEP occurs only for primary emissions. $\mathrm{NO}_{2}$ is calculated from $\mathrm{NO}_{x}$ and $\mathrm{O}_{x}$ using the same travel time parameterisation described in Denby et al. (2020) but applied to annual mean wind speeds, photo-dissociation rates, and concentrations. To account for non-linearity in the $\mathrm{NO}_{2}$ chemistry, when calculating with annual means, an additional frequency distribution correction factor is imple-
Table 1. Initial dispersion $\left(\sigma_{z 0}\right)$ and emission height $\left(h_{\mathrm{emis}}\right)$ for the three downscaled sources for all primary pollutants.

\begin{tabular}{lll}
\hline Source & $\begin{array}{l}\text { Initial dispersion } \\
\left(\sigma_{z 0}\right)\end{array}$ & $\begin{array}{l}\text { Emission height } \\
\left(h_{\mathrm{emis}}\right)\end{array}$ \\
\hline Traffic (GNFR6) & $2 \mathrm{~m}$ & $1 \mathrm{~m}$ \\
Residential heating (GNFR3) & $10 \mathrm{~m}$ & $15 \mathrm{~m}$ \\
Shipping (GNFR7) & $15 \mathrm{~m}$ & $70 \mathrm{~m}$ \\
\hline
\end{tabular}

mented (Sect. 2.4). Annual mean downscaled $\mathrm{O}_{3}$ is also determined using this same parameterisation.

To improve efficiency of the calculations, Europe is split into a number of tiles that cover the European land domain. For the $100 \mathrm{~m}$ resolution mapping calculations there are 1097 tiles, each of which is $100 \mathrm{~km} \times 100 \mathrm{~km}$. These tiling regions are shown in Fig. 2.

\subsection{The uEMEP proxy data}

We use road data from OSM to redistribute the traffic emissions. Though the spatial coverage of OSM is very good, it does not contain actual traffic data. Redistribution of the emission data is achieved by weighting the different road categories provided in OSM. The following road categories are considered: motorway, trunk, primary, secondary, tertiary, unclassified, and residential. Each is weighted relative to the other so that emissions can be redistributed and at- 


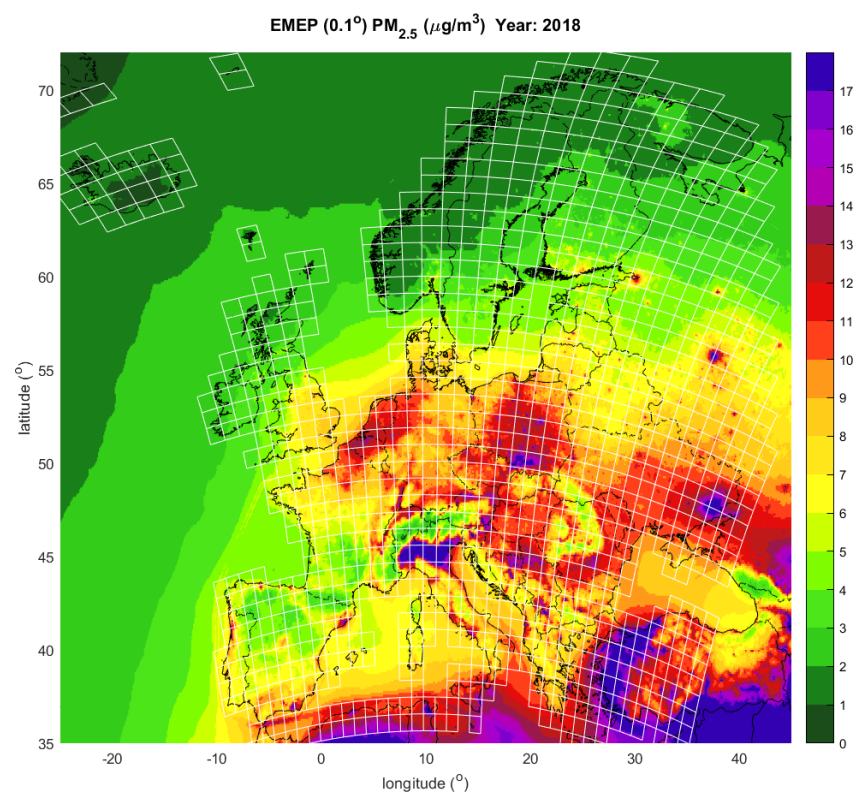

Figure 2. Annual mean $\mathrm{PM}_{2.5}$ concentrations calculated with the EMEP model at $0.1^{\circ}$ for 2018. Shown are the uEMEP tiling regions used in the calculations. In total, $1097100 \mathrm{~km} \times 100 \mathrm{~km}$ tiles with $100 \mathrm{~m}$ resolution are used to model Europe.

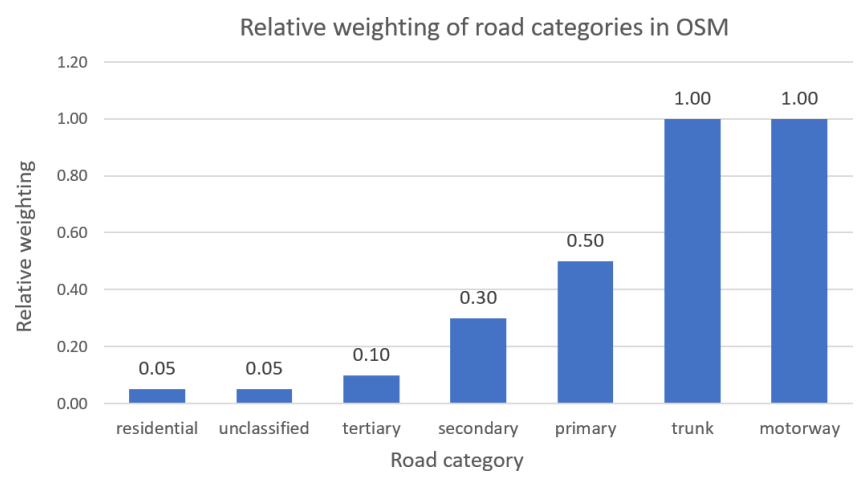

Figure 3. Weighting of the OpenStreetMap road categories used to redistribute EMEP traffic emissions for downscaling. Applied to all primary pollutants.

tributed to the road links. Estimates of the weights are based on the representative average daily traffic (ADT) for different road categories for Norwegian average road situations. The weighting currently employed for the redistribution is shown in Fig. 3. It is also worth noting that for major roads, such as motorways, OSM often represents these as dual carriageways, i.e. as two separate road links. In these cases the weighting of a motorway will be twice that indicated here. Sensitivity tests with alternative weighting (Sect. 5.2) show that the choice of weighting does impact the results but that the current choice provides close to optimal spatial correlation when compared to measurements.
A global population dataset from the GHS is used as the proxy for redistributing residential heating emissions. We choose the highest available resolution of $9 \operatorname{arcsec}\left(0.0025^{\circ}\right)$ from the year 2015. The coordinate system is WGS84. This dataset indicates the distribution of population as the number of people per cell. A number of alternative formulations of the population proxy, as well as an alternative proxy based on building density, are assessed in Sect. 5.3

AIS data for shipping emissions are provided by the Norwegian Coastal Administration. The raw data, which contain a list of instantaneous point emissions, are averaged over the year 2017 and gridded to $0.0025^{\circ}$. Though these data are actual emissions we still use them as proxy data to redistribute EMEP gridded emissions to be consistent in the methodology.

\section{4 uEMEP chemistry parameterisation for annual mean $\mathrm{NO}_{2}$}

The uEMEP downscales only primary pollutants. It is thus necessary to apply chemistry parameterisations to the $\mathrm{NO}_{x}$ and EMEP $\mathrm{O}_{3}$ concentrations to derive downscaled $\mathrm{NO}_{2}$ and $\mathrm{O}_{3}$ concentrations. Two methods for doing this are described in Denby et al. (2020): one for hourly concentrations using a weighted travel time parcel method and the other for annual means, which is based on a simple empirical relationship between observed $\mathrm{NO}_{2}$ and $\mathrm{NO}_{x}$. It is desirable to apply the model-based chemistry scheme rather than an empirical scheme; however, due to the non-linearity of the $\mathrm{NO}_{2}$ chemistry the chemical scheme cannot be directly applied to annual mean concentrations.

To solve this, chemistry is not calculated on just a single annual mean value for $\mathrm{NO}_{x}$ and $\mathrm{O}_{3}$ but on a frequency distribution for these parameters that represent the variability over a year. This can be illustrated for the photostationary case in which the $\mathrm{NO}_{2}$ concentrations can be derived from $\mathrm{NO}_{x}$ and $\mathrm{O}_{x}$ using

$$
\begin{aligned}
{\left[\mathrm{NO}_{2}\right]=} & \frac{1}{2}\left(\left(\left[\mathrm{NO}_{x}\right]+\left[\mathrm{O}_{x}\right]+J / k_{1}\right)\right. \\
& \left.-\sqrt{\left(\left[\mathrm{NO}_{x}\right]+\left[\mathrm{O}_{x}\right]+J / k_{1}\right)^{2}-4\left[\mathrm{NO}_{x}\right]\left[\mathrm{O}_{x}\right]}\right),
\end{aligned}
$$

where the concentrations are annual mean values in molecules per cubic centimetre (molec. $\mathrm{cm}^{-3}$ ), $k_{1}$ is the production reaction rate, and $J$ the photo-dissociation rate for $\mathrm{NO}_{2}$. If the frequency distribution for the three annual mean variables $\left[\mathrm{NO}_{x}\right],\left[\mathrm{O}_{x}\right]$, and $J / k_{1}$ is known then we can integrate over Eq. (1) using these distributions as weighting functions. An appropriate probability distribution function for the concentrations is the log-normal distribution, which can be written as

$\mathrm{PDF}_{x}=\frac{1}{x \sigma \sqrt{2 \pi}} \exp \left(-\frac{(\log (x)-\mu)^{2}}{2 \sigma^{2}}\right)$, 
where the log-normal parameters $\mu$ and $\sigma$ are determined from the mean $(m)$ and the standard deviation $(s)$ by

$$
\mu=\log \left(\frac{m^{2}}{\sqrt{m^{2}+s^{2}}}\right) \text { and } \sigma^{2}=\log \left(1+\frac{s^{2}}{m^{2}}\right) .
$$

The frequency distribution of $J$ is not log-normally distributed, since it is dependent on the solar zenith angle (ZA) and various other meteorological parameters, such as cloud cover and water vapour content. The EMEP model uses lookup tables based on precalculated $J$ values from the Phodis model (Jonson et al., 2000). In order to implement the frequency distribution of $J$ in uEMEP a power-law fit is made to the tabulated values. This can be written as

$$
J=C_{j} \cos (\mathrm{ZA})^{-p_{j}},
$$

where $C_{j}$ is a constant that is normalised out when producing the normalised frequency distribution and $p_{j}=0.28$. The standard deviation of $k_{1}$, dependent on air temperature, is significantly smaller than for $J$ so it is treated as a constant.

A new value $\left[\mathrm{NO}_{2}\right]_{\text {pdf }}$ can then be determined using these frequency distributions:

$$
\begin{aligned}
& {\left[\mathrm{NO}_{2}\right]_{\text {pdf }}} \\
& =\iint_{0}^{\infty} \int\left[\mathrm{NO}_{2}\right] \mathrm{PDF}_{\text {ox }} \mathrm{PDF}_{\text {nox }} \mathrm{PDF}_{j} \mathrm{~d}\left[\mathrm{NO}_{x}\right] \mathrm{d}\left[\mathrm{O}_{x}\right] \mathrm{d} J \text {, }
\end{aligned}
$$

and a correction term showing its difference from the mean is defined as

$$
f_{\text {no2,pdf }}=\frac{\left[\mathrm{NO}_{2}\right]_{\mathrm{pdf}}}{\left[\mathrm{NO}_{2}\right]_{\text {mean }}}-1 \text {. }
$$

When calculating in three orthogonal dimensions it is assumed there is no correlation between the variables.

To implement this procedure the standard deviation $s$ must be known for $\mathrm{NO}_{x}$ and $\mathrm{O}_{x}$. Values for $s_{\text {nox }}$ and $s_{\mathrm{ox}}$ have been derived from earlier model calculations for Norwegian stations. Linear regression provides robust values for $s_{\mathrm{Ox}} / m_{\mathrm{ox}}$ and $s_{\text {nox }} / m_{\text {nox }}$ of 0.21 and 1.14 , respectively (Fig. S5). The variability of $\mathrm{NO}_{x}$ reflects the variability of the traffic emissions for stations within the influence of traffic, and this should be generally applicable throughout Europe. A total of 72 sites are used for the calculation. The calculation of the distribution correction is carried out numerically after calculation of the $\mathrm{NO}_{2}$ concentrations.

Implementation of the frequency distribution for concentrations has a significant impact, with a general reduction in $\mathrm{NO}_{2}$ concentrations compared to the annual mean calculation using Eq. (1). This reduction leads to correction terms $\left(f_{\text {no2,pdf }}\right)$ of between $0 \%$ and $-25 \%$. The highest corrections occur around $\mathrm{NO}_{x}=\mathrm{O}_{x}$, where Eq. (1) shows the most non-linear behaviour. On average for all station sites in Europe, around a $-16 \%$ reduction on the initially calculated
$\left[\mathrm{NO}_{2}\right]_{\text {mean }}$ has been determined. In contrast to the distribution correction for concentrations, the distribution correction for $J$ leads to an increase in $\mathrm{NO}_{2}$ of around $6 \%$. This is because roughly half of the frequency distribution for $J$ is 0 , i.e. night-time, when there is no photo-dissociation. In Sect. 5.5 the impact of this and other chemistry schemes is further discussed. More information concerning this scheme is contained in the Supplement.

\section{Example maps}

In this section we present example maps that are generated from the EMEP model and uEMEP simulations. The $100 \mathrm{~km}$ example tiles are shown in Figs. 4-6, demonstrating the original EMEP model calculations and the downscaled maps using uEMEP for $\mathrm{NO}_{2}, \mathrm{O}_{3}$, and $\mathrm{PM}_{2.5}$. The uEMEP calculations are made on an $x-y$ projected map commonly used for European mapping. The projection used is the European ETRS89-LAEA projection (EPSG: 3035). Maps presented are shown on latitude and longitude, which means that the projected uEMEP tiled maps do not necessarily follow the north-south direction.

The downscaled maps resolve more variability between stations. Compared with the EMEP model maps, uEMEP maps have higher concentrations of $\mathrm{NO}_{2}$ and $\mathrm{PM}_{2.5}$, as well as lower concentration of $\mathrm{O}_{3}$, in heavy traffic and populated areas due to the high-resolution proxy dataset.

\section{Validation}

Observed annual mean concentrations of $\mathrm{NO}_{2}, \mathrm{PM}_{2.5}, \mathrm{PM}_{10}$, and $\mathrm{O}_{3}$ from AIRBASE (European Environment Agency, 2018) are used for comparison with both the EMEP model and uEMEP calculations. All valid AIRBASE stations with more than $75 \%$ coverage are used in the validation and are assumed to be sited at $3 \mathrm{~m}$ above the surface. Results for the year 2018 are presented. Results focus on the spatial correlation, expressed in terms of the coefficient of determination $\left(r^{2}\right)$, and on the relative bias (bias). For station sites the downscaling with uEMEP is performed on $25 \mathrm{~m}$ sub-grids, which is of sufficient resolution to spatially represent traffic sites. However, since the Gaussian model used does not take into account buildings or obstacles, traffic sites in street canyons or built-up areas may be underestimated. A study by Lefebvre et al. (2013) in Antwerp, where both Gaussian and street canyon models were applied at 15 street canyon modelling sites, showed an average street canyon modelling increment of just $11 \%$ for $\mathrm{NO}_{2}$. We include all available sites in this study because in Europe the majority of traffic sites appear not to be street canyons, though information on this is unclear (Tarrasón et al., 2021). Also, even without including obstacles, the increased model resolution (up to $25 \mathrm{~m}$ ) allows the concentration gradients at roadsides to be better described. 

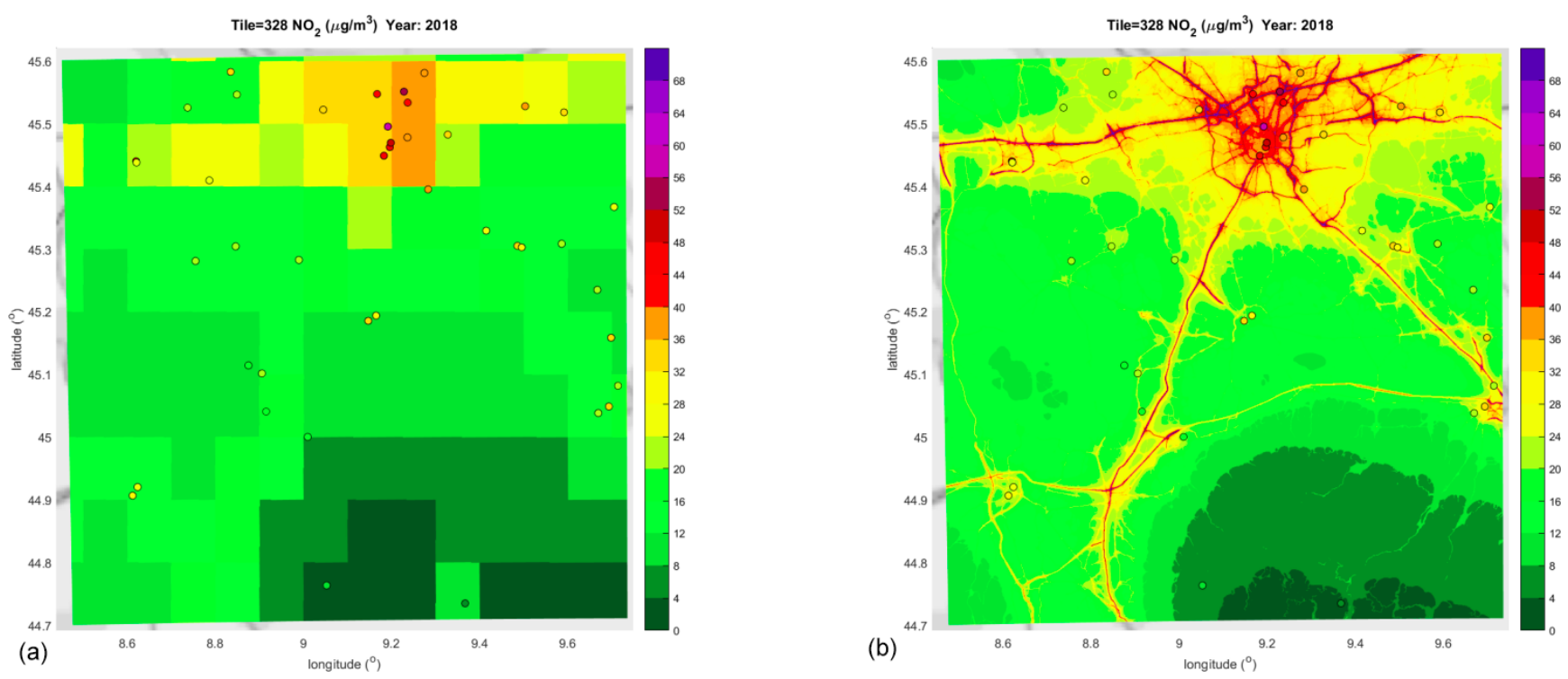

Figure 4. Calculated $\mathrm{NO}_{2}$ concentrations in the $100 \mathrm{~km}$ tile (no. 328) for 2018, which is part of the all European calculation at $100 \mathrm{~m}$ resolution. (a) The EMEP model calculation at $0.1^{\circ}$ and (b) the uEMEP calculation at $100 \mathrm{~m}$ resolution. The city in this tile is Milan. AIRBASE stations are shown as circles.
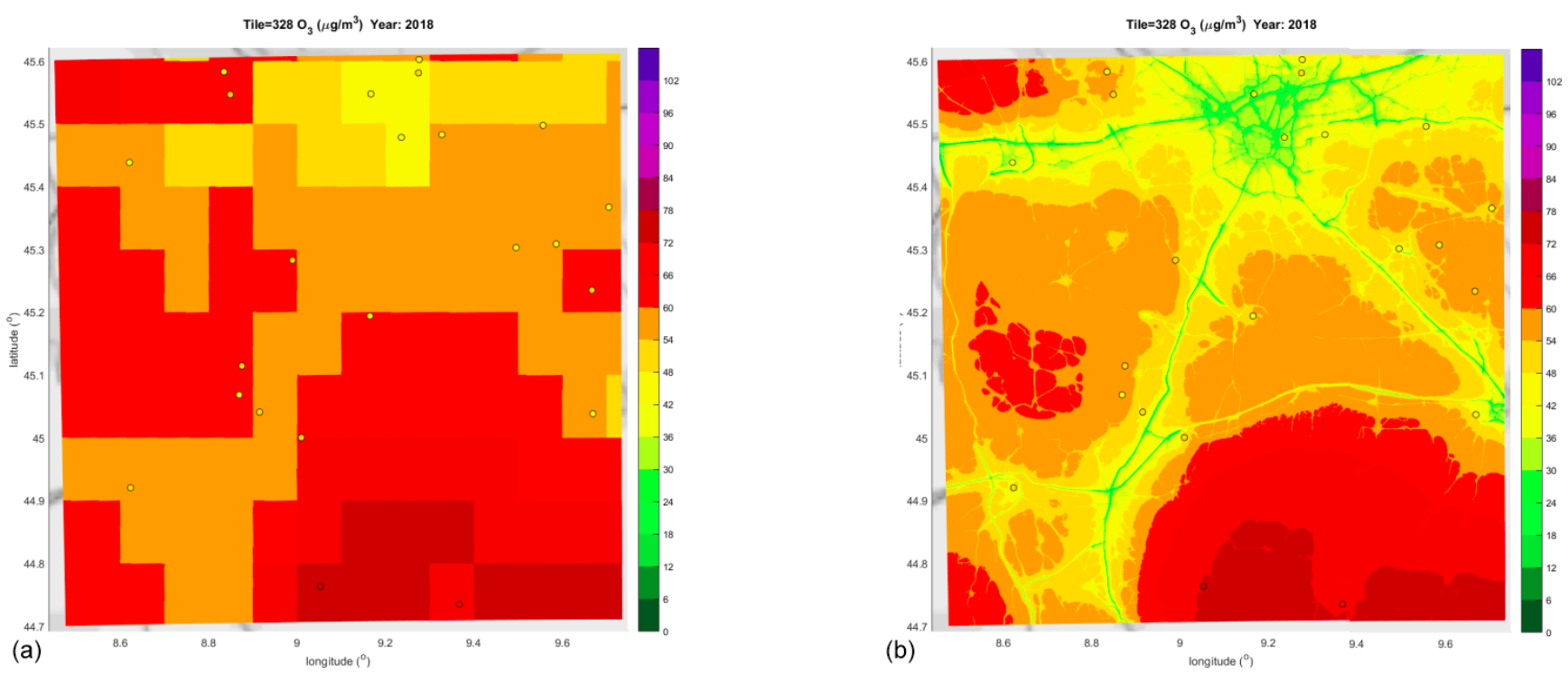

Figure 5. Calculated $\mathrm{O}_{3}$ concentrations in the $100 \mathrm{~km}$ tile (no. 328) for 2018, which is part of the all European calculation at $100 \mathrm{~m}$ resolution. (a) The EMEP model calculation at $0.1^{\circ}$ and (b) the uEMEP calculation at $100 \mathrm{~m}$ resolution. The city in this tile is Milan. AIRBASE stations are shown as circles. This is the same tile shown in Fig. 4.

\section{$4.1 \mathrm{NO}_{2}$}

In Figs. S6 and $\mathrm{S} 7$ scatter plots for $\mathrm{NO}_{2}$ are shown for each country and Europe as a whole. These results are summarised in Fig. 7 where the annual mean concentration and spatial correlation are shown.

In a majority of countries the spatial correlation for $\mathrm{NO}_{2}$ is more than doubled when implementing uEMEP. The two exceptions are Ireland (IE), where the spatial correlation hardly changes with the downscaling, and Bosnia and Herzegovina (BA), where the spatial correlation is significantly reduced. Both these countries have very few stations. The highest spatial correlation is for Poland (PL) with $r^{2}=0.85$.

It is worth noting that the average spatial correlation per country is $r^{2}=0.62$, which is higher than the spatial correlation when assessed for all stations in Europe $\left(r^{2}=0.57\right)$. This indicates that some of the variability occurs between countries and can be interpreted to reflect differences related 

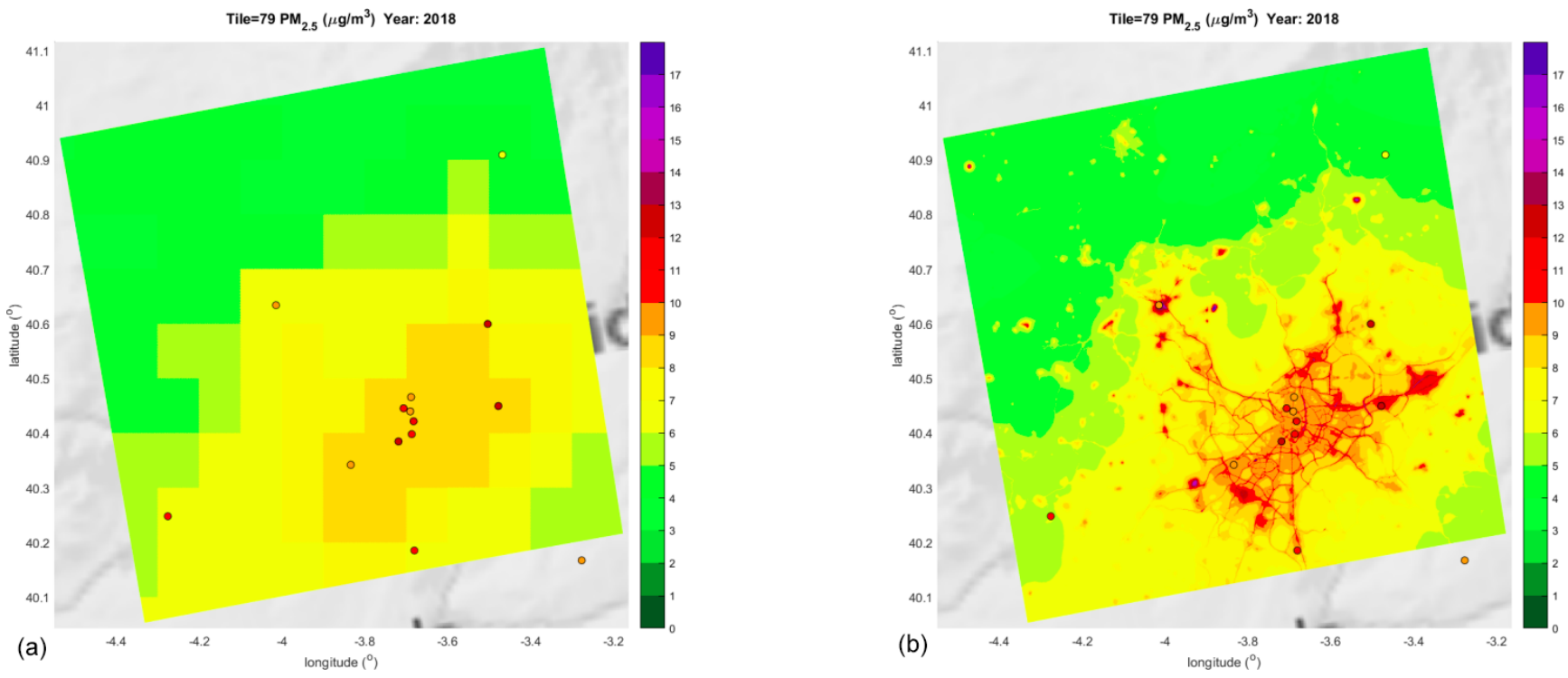

Figure 6. Calculated $\mathrm{PM}_{2.5}$ concentrations in the $100 \mathrm{~km}$ tile (no. 79) for 2018, which is part of the all European calculation at $100 \mathrm{~m}$ resolution. (a) The EMEP model calculation at $0.1^{\circ}$ and (b) the uEMEP calculation at $100 \mathrm{~m}$ resolution. The city in this tile is Madrid. AIRBASE stations are shown as circles.

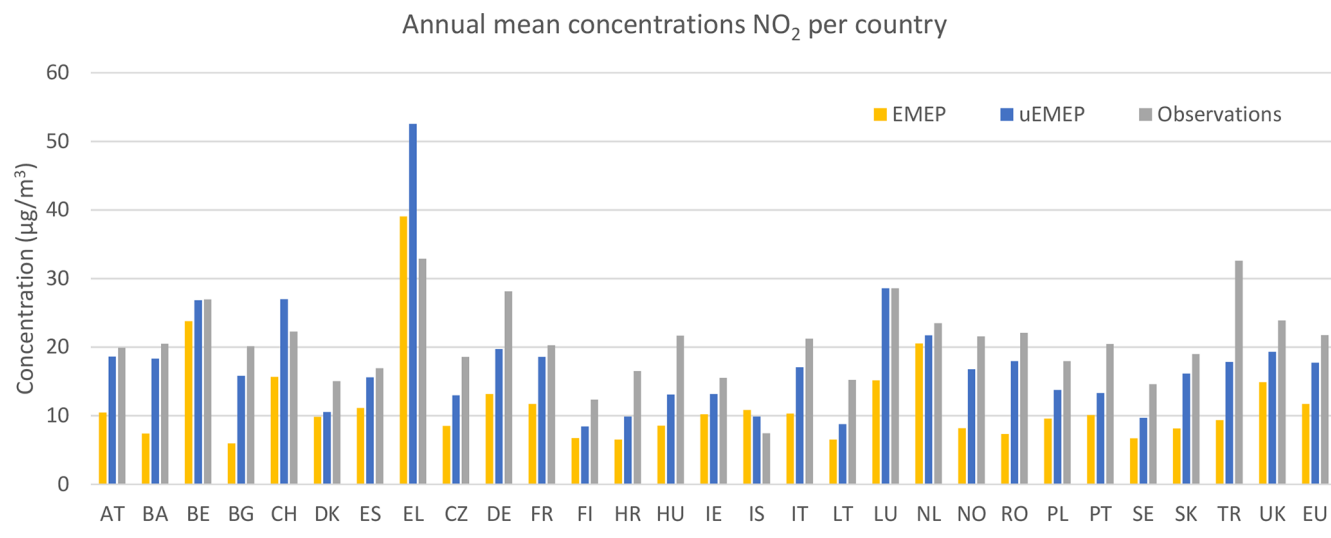

Spatial correlation $\left(\mathrm{r}^{2}\right) \mathrm{NO}_{2}$ per country

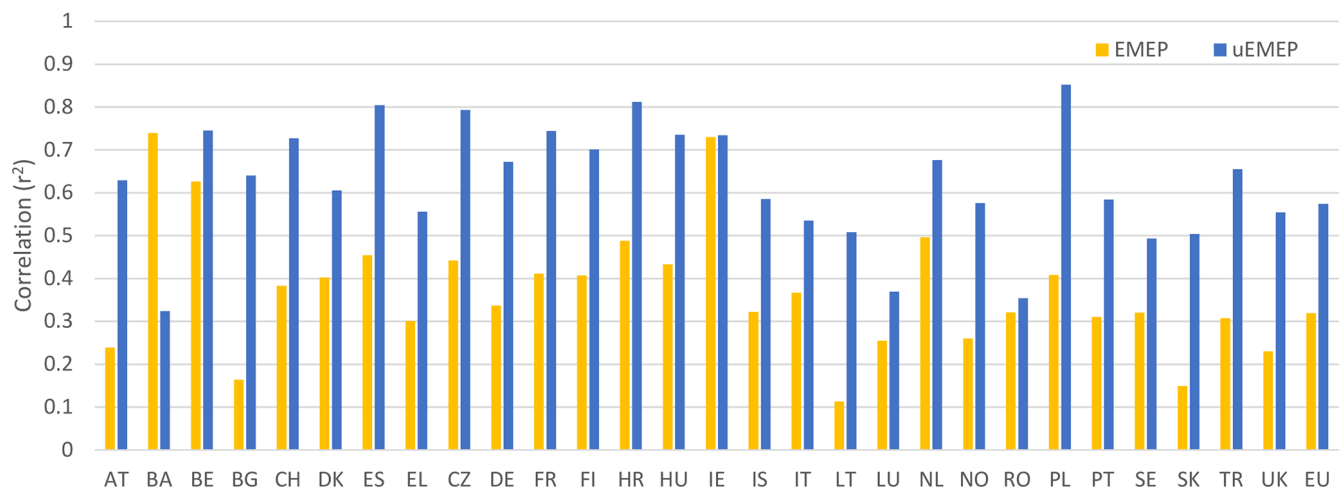

Figure 7. Annual mean $\mathrm{NO}_{2}$ concentrations and spatial correlation (coefficient of determination $r^{2}$ ) per country for 2018 calculated with the EMEP model and UEMEP compared to AIRBASE observations. Only countries with 10 or more stations are shown, but all stations are included in the final EU result. A total of 3313 stations are included in the comparison. 
to emission reporting from each country. If the $\mathrm{NO}_{x}$ emissions from individual countries have uncorrelated bias, this will reduce the overall spatial correlation.

The relative bias is improved for all countries with the exception of Greece (EL), which is the only country with a significant positive bias. Overall for Europe, bias is improved from $-46 \%$ for the EMEP model to $-18 \%$ when using UEMEP. Of the 28 countries with 10 or more monitoring sites, 18 of these have an absolute bias less than $25 \%$ after downscaling. Turkey (TR) has the largest negative bias, after downscaling, of $-45 \%$.

\section{$4.2 \quad \mathrm{PM}_{2.5}$}

In Figs. S8 and S9 scatter plots for $\mathrm{PM}_{2.5}$ are shown for each country and Europe as a whole. These results are summarised in Fig. 8 where the annual mean concentration and spatial correlation are presented.

Unlike the $\mathrm{NO}_{2}$ downscaling, there is generally no improvement in the spatial correlation when applying uEMEP for $\mathrm{PM}_{2.5}$. Only 6 out of 17 countries show improved spatial correlation, and overall for Europe there is a slight decrease from $r^{2}=0.49$ for the EMEP model to 0.46 for uEMEP. This result is further discussed in Sect. 6 .

The relative bias, however, is reduced for almost all countries. For Europe as a whole the relative bias went from $-21 \%$ for the EMEP model to $-11 \%$ for uEMEP. Only the three countries Austria (AT), Sweden (SE), and Finland (FI), which had almost no bias with the EMEP model calculation, achieve a positive bias with UEMEP.

\section{3 $\mathrm{PM}_{10}$}

In Figs. S10 and S11 scatter plots for $\mathrm{PM}_{10}$ are shown for each country and Europe as a whole. These are summarised in Fig. 9.

The results for $\mathrm{PM}_{10}$ are similar to those for $\mathrm{PM}_{2.5}$. In this case though the majority of countries, 21 out of 27 , have improved spatial correlation with the application of UEMEP. The spatial correlation for all of Europe using uEMEP is unaltered compared to the EMEP model calculation, with $r^{2}=0.34$. This is lower than the spatial correlation found for $\mathrm{PM}_{2.5}$ by around 0.12 .

As with $\mathrm{PM}_{2.5}$ the relative bias is reduced with the uEMEP downscaling. For Europe we see that the relative bias went from $-39 \%$ for the EMEP model to $-30 \%$ for uEMEP.

\section{$\begin{array}{ll}4.4 & \mathrm{O}_{3}\end{array}$}

In Figs. $\mathrm{S} 12$ and $\mathrm{S} 13$ scatter plots for $\mathrm{O}_{3}$ are shown for each country and Europe as a whole. These are summarised in Fig. 10.

Ozone is generally reduced with the downscaling due to an increase in $\mathrm{NO}_{x}$ concentrations. In general for Europe we see a reduced positive bias from $+16 \%$ for the EMEP model to $+11 \%$ for uEMEP. Spatial correlation is also improved in
21 of the 24 countries. The only countries to show significant degradation in the downscaling results are Switzerland $(\mathrm{CH})$ and Greece (EL). This is likely due to the overestimated $\mathrm{NO}_{x}$ concentrations there (Fig. 7).

\section{Sensitivity studies}

In this section we present the results of several sensitivity calculations using uEMEP. These include sensitivity to sub-grid resolution, traffic emission proxies, residential combustion emission proxies, alternative bottom-up emissions in Norway, and the $\mathrm{NO}_{2}$ chemistry scheme.

\subsection{Sensitivity to resolution}

When calculating concentrations at station positions a grid resolution of $25 \mathrm{~m}$ is used. However, when mapping all of Europe a lower resolution of $100 \mathrm{~m}$ is employed. In Fig. 11 we show the results of a change in resolution of the annual mean $\mathrm{NO}_{2}$ and $\mathrm{PM}_{2.5}$ concentrations for resolutions from 25 to $500 \mathrm{~m}$.

For $\mathrm{NO}_{2}$ both bias and spatial correlation improve with increasing resolution. The $100 \mathrm{~m}$ calculations are on average $4 \%$ lower than the $25 \mathrm{~m}$ calculations. For $\mathrm{PM}_{2.5}$ there is little change in bias between the different resolutions. Both shipping and residential combustion sources are only provided at $250 \mathrm{~m}$, so any further change in model results at lower resolutions will be due to the traffic contribution only. Spatial correlation is basically unchanged for $\mathrm{PM}_{2.5}$ at all resolutions.

\subsection{Sensitivity to OSM weighting}

In Fig. 3 the weighting imposed on the OSM road categories is shown. This weighting specifies the relative contribution of the different road categories to the redistribution of the gridded traffic emissions in uEMEP. This weighting is based on an analysis of Norwegian traffic data, but it is worthwhile to assess the sensitivity of the calculated $\mathrm{NO}_{2}$ concentrations using different weights. To assess this sensitivity a power law is applied to the weighting. For power indices greater than 1 more weighting is applied to the major roads, and for powerlaw indices less than 1 more weight is applied to the minor roads. The different weights for the different power-law indices are shown in Fig. 12. The results of this sensitivity test, presented in terms of relative bias and spatial correlation $\left(r^{2}\right)$, are shown in Fig. 13.

Bias is quite strongly affected by the change in weighting. Higher concentrations are calculated when more weight is given to the minor roads. This is likely because most measurement sites are not on major roads. Increasing the weighting to minor roads will generally increase the urban background levels. The spatial correlation is among the highest for the current weighting with a power index of 1 . This confirms that the initial estimate, based on Norwegian traffic, re- 

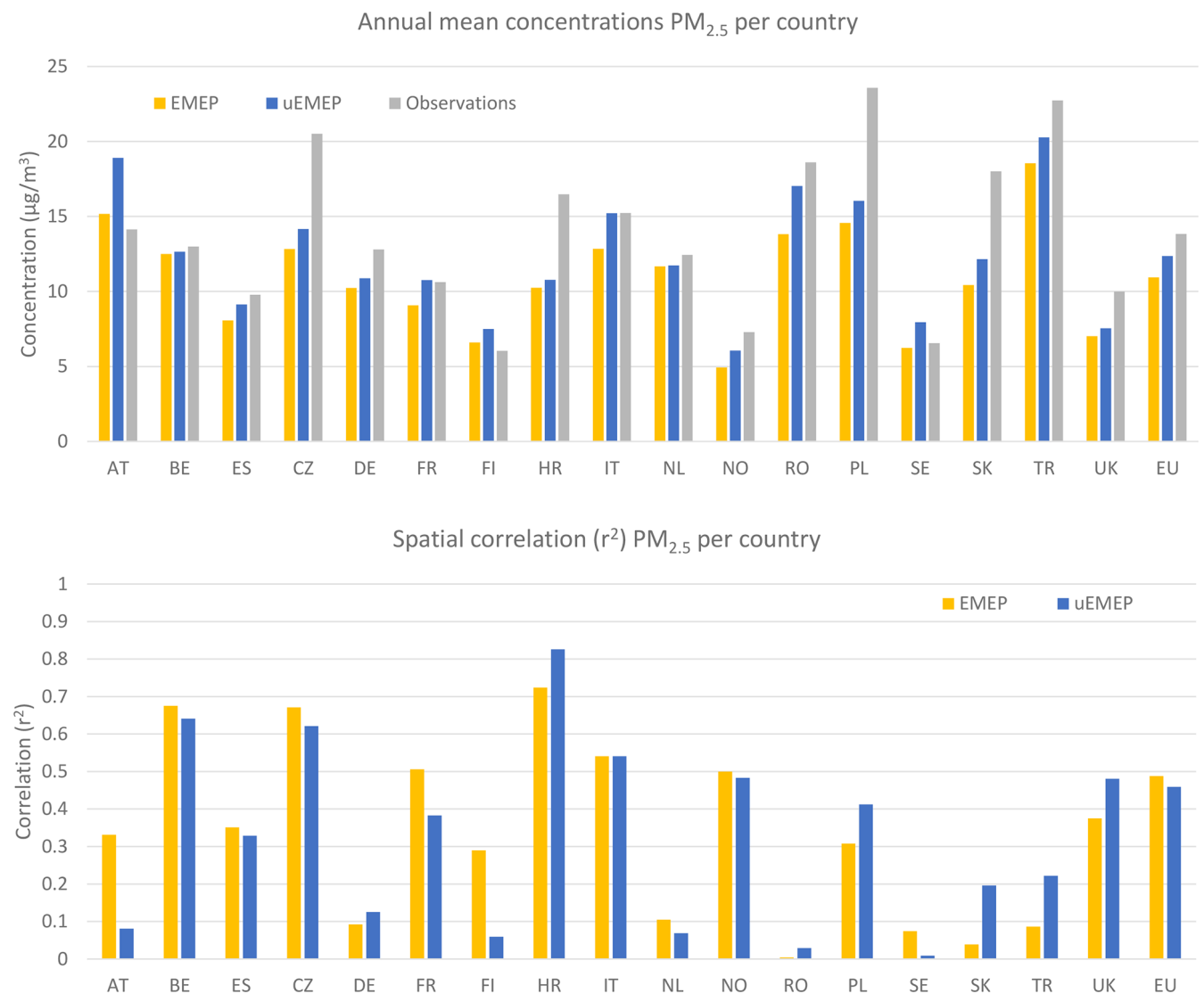

Figure 8. Annual mean $\mathrm{PM}_{2.5}$ concentrations and spatial correlation (coefficient of determination $r^{2}$ ) per country for 2018 calculated with the EMEP model and UEMEP compared to AIRBASE observations including all types of stations. Only countries with 10 or more stations are shown, but all stations are included in the final EU result. A total of 1376 stations are included in the comparison.

flects a good general distribution of traffic in Europe. If real traffic volume were available the weighting would be more precise. Tests on Norwegian data in Sect. 5.4 confirm that spatial correlation is significantly improved when using real traffic data for the redistribution weighting.

\subsection{Sensitivity to the residential combustion emission proxy}

For the $\mathrm{PM}_{2.5}$ calculations presented in Sect. 4.2 population density data at $0.0025^{\circ}$ have been used to redistribute the residential combustion emissions in uEMEP. The results indicate a slightly reduced spatial correlation but also with an improved negative bias. In this section we assess the sensitivity of the redistribution proxy to a number of alternative proxies. Firstly a power law is applied to the population density data. A lower power-law index will reduce the weighting towards highly populated regions. A power-law index of 0 will work as a mask, redistributing the EMEP emissions evenly to any $250 \mathrm{~m}$ sub-grid that contains population. As an alternative to the population data, building density data have also been extracted from the OpenStreetMap dataset. These have also been placed on a $0.0025^{\circ}$ grid for all of Europe.
Two alternatives with this proxy are tested: the first using building density as the weighting proxy and the second using building density masked with population so that only areas with both buildings and population are used for redistribution. In addition to the alternative proxy data the sensitivity of the calculations to emission height, currently set to $15 \mathrm{~m}$, is also assessed.

The results are shown in Fig. 14. Here we see that a power law of 0.25 gives slightly improved spatial correlation and that the use of building density also slightly improves spatial correlation compared to population. However, none of the alternative proxies significantly improve the spatial distribution of $\mathrm{PM}_{2.5}$ and none attain the spatial correlation of the EMEP model calculations at $0.1^{\circ}$. There is a general trend for reduced negative bias to lead to reduced spatial correlation in all calculations, so when the contribution from the downscaled residential combustion increases spatial correlation decreases. This implies that the redistribution is not improving the results.

In addition to the proxy sensitivity the result of the EMEP model calculation wherein all local EMEP model grid contributions $\left( \pm 1^{\circ}\right)$ have been removed is shown in Fig. 14. This 


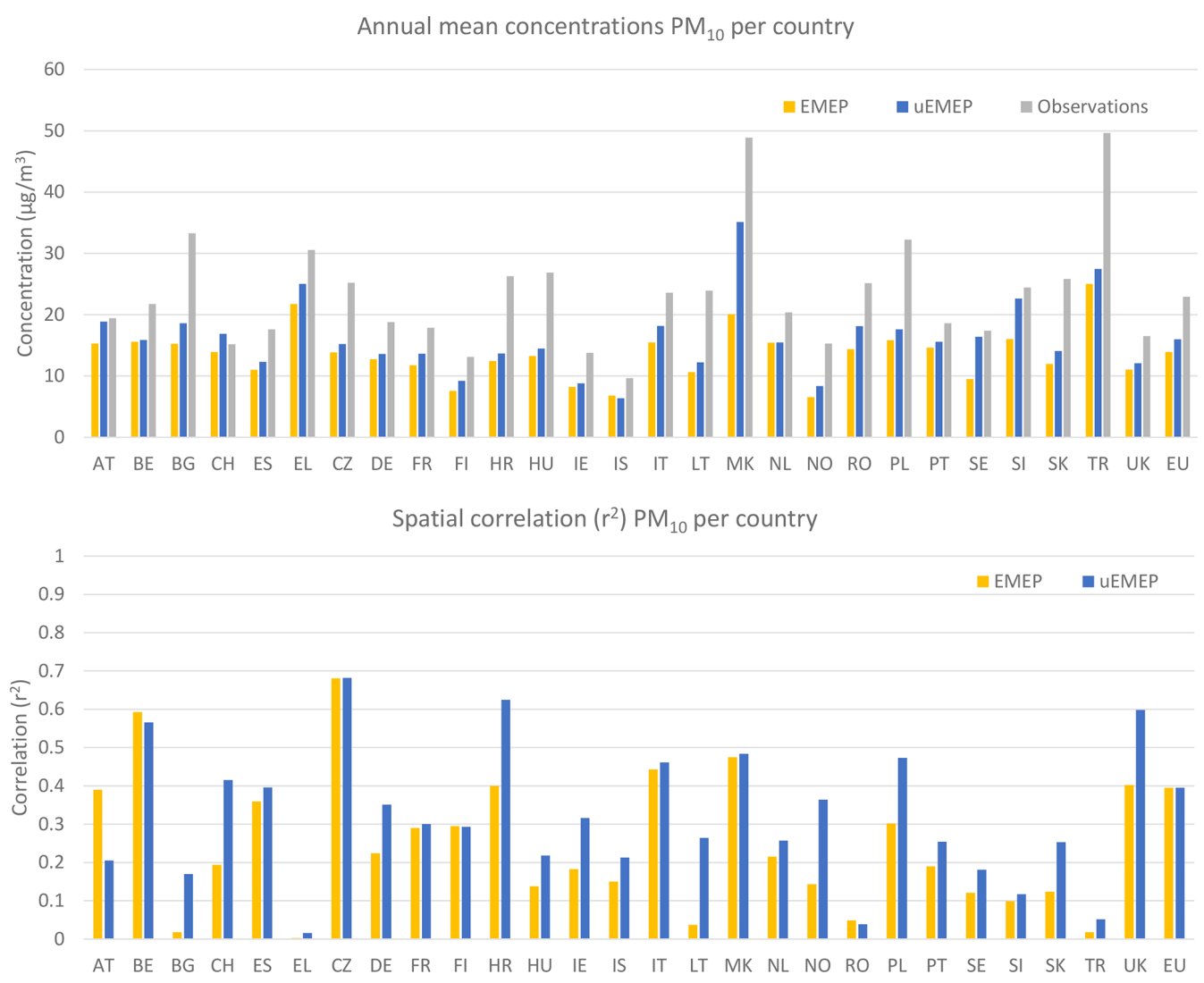

Figure 9. Annual mean $\mathrm{PM}_{10}$ concentrations and spatial correlation (coefficient of determination $r^{2}$ ) per country for 2018 calculated with the EMEP model and uEMEP compared to AIRBASE observations including all types of stations. Only countries with 10 or more stations are shown, but all stations are included in the final EU result. A total of 2891 stations are included in the comparison.

shows firstly that around $10 \%$ of the $\mathrm{PM}_{2.5}$ in the EMEP model comes from within this local region and that the inclusion of these emissions does add to improved spatial correlation at the EMEP model $0.1^{\circ}$ scale, from $r^{2}=0.467$ to 0.488 . Here we see more clearly that while the bias is improved by downscaling the spatial correlation is not and is similar to the spatial correlation obtained from the non-local contributions. However, it is possible to achieve improved spatial correlation when more appropriate downscaling proxies are used. This is presented in Sect. 5.4.

\subsection{Results of improved emission data in Norway}

Throughout the uEMEP downscaling simulations we used the $0.1^{\circ}$ country-reported emission data and redistributed them using population, OpenStreetMap, and AIS shipping data as redistribution proxies. However, many countries have more detailed emission data sets, including Norway, that could be used to improve the downscaling calculations. To test the impact of more realistic spatial distributions of emissions, the emission and emission proxy data used in Norway are replaced in the EMEP model and uEMEP calculations with the emission data currently used in the national air quality forecasting in Norway. Details surrounding these emissions can be found in Denby et al. (2020) and Grythe et al. (2019). The most important differences between the Norwegian and European emissions and emission proxy data include the fact that (1) traffic volume data from the Norwegian national road database are used instead of OSM weighting. Exhaust emissions are based on emission factors using a bottom-up methodology, and $\mathrm{NO}_{x}$ emissions are additionally corrected for temperature. (2) The non-exhaust road dust emissions are calculated with the NORTRIP model (Denby et al., 2013a, b), which are significantly larger than the current national estimates reported for Norway. (3) The total Norwegian residential heating emissions of PM are the same for both the Norwegian and the European emissions, but the Norwegian emissions have been redistributed using the MetVed model (Grythe et al., 2019), which uses much more detailed information than just population to distribute the residential heating emissions at $250 \mathrm{~m}$. (4) The Norwegian emissions and the uEMEP proxy data are entirely consistent with each other since the Norwegian emissions are aggregated grid emissions based on the fine-scale emission data.

We make four separate downscaling calculations for Norway using the two emissions "European emissions" and "Norwegian emissions" as well as the two high-resolution 

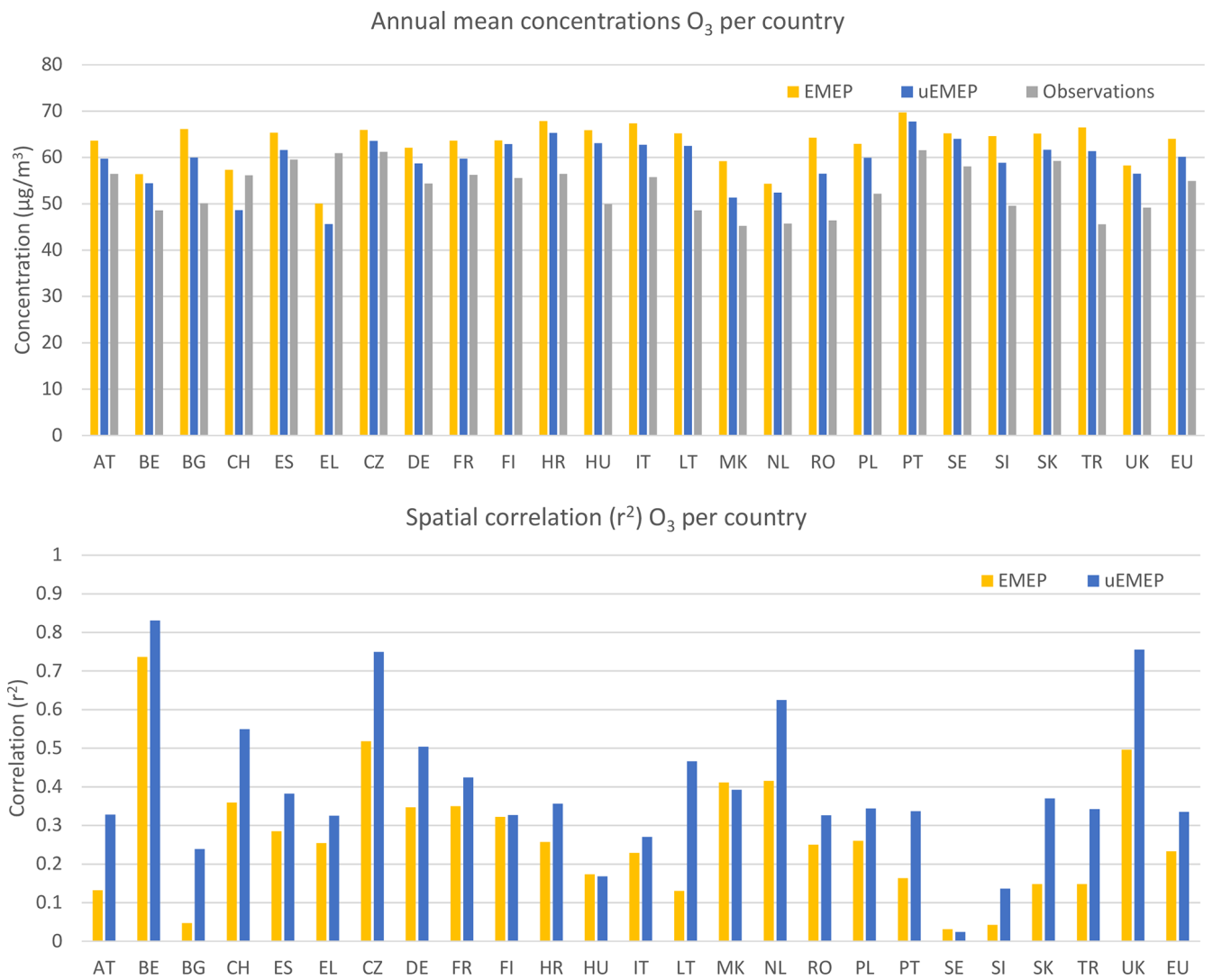

Figure 10. Annual mean $\mathrm{O}_{3}$ concentrations and spatial correlation (coefficient of determination $r^{2}$ ) per country for 2018 calculated with the EMEP model and uEMEP compared to AIRBASE observations including all types of stations. Only countries with 10 or more stations are shown, but all stations are included in the final EU result. A total of 1974 stations are included in the comparison.
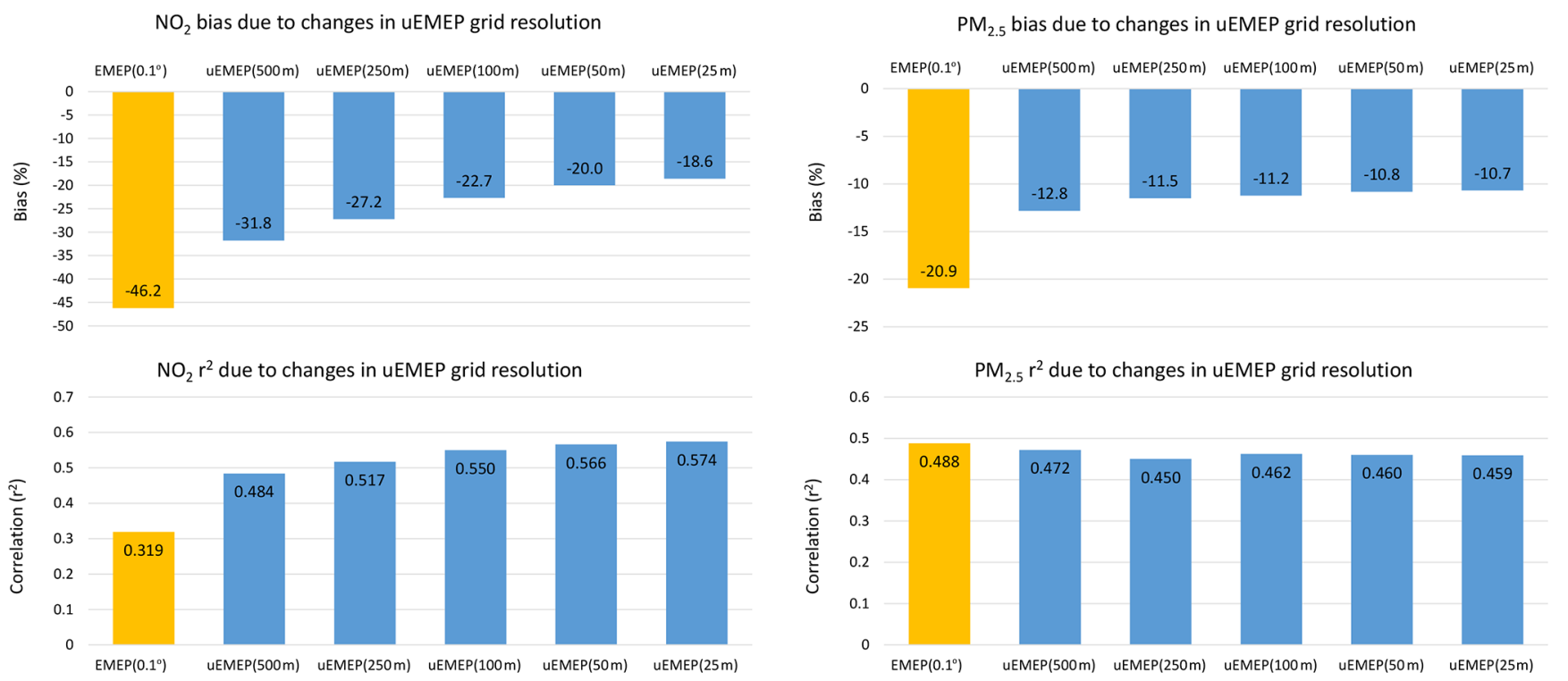

Figure 11. Change in bias and spatial correlation (coefficient of determination $r^{2}$ ) as a result of changes in uEMEP resolution. Shown are the results for $\mathrm{NO}_{2}$ and $\mathrm{PM}_{2.5}$. Also included is the EMEP model $0.1^{\circ}$ calculation in yellow. The results are based on the European calculations, and all available AIRBASE stations are included. 


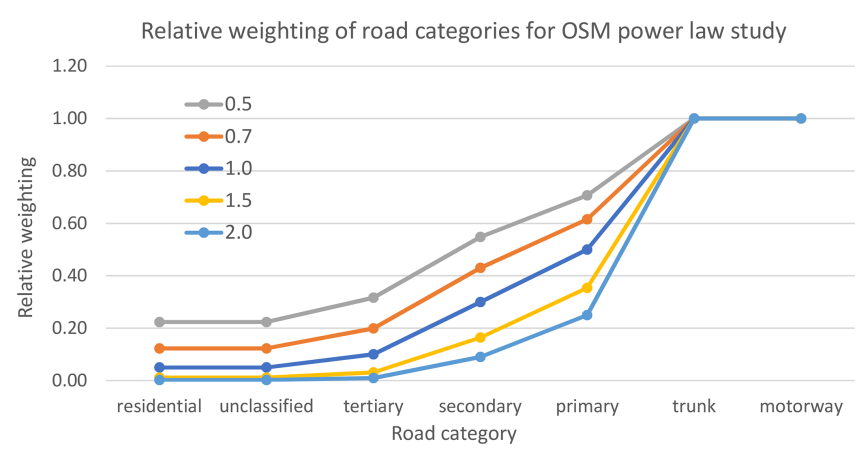

Figure 12. OSM weighting, relative to motorways, that results with a change in the power-law index when applied to the initial weights. The scenarios are tested in the European calculations.

proxy datasets "European proxy downscaling" and "Norwegian proxy downscaling", respectively. Shipping is not changed in these simulations, and in this case the calculation year is 2017. Though the resolution of the EMEP model in the Norwegian forecasting system is nominally $2.5 \mathrm{~km}$, for these simulations we use the same $0.1^{\circ}$ EMEP model grid resolution. The results are shown in Fig. 15 for $\mathrm{NO}_{2}, \mathrm{PM}_{2.5}$, and $\mathrm{PM}_{10}$ with the relative bias $(\%)$ and spatial correlation $\left(r^{2}\right)$ presented.

For $\mathrm{NO}_{2}$ in Norway the large negative bias seen in the EMEP model is almost completely removed by the use of the traffic downscaling using either the Norwegian or European emission data. On a national level the local Norwegian (bottom-up) traffic $\mathrm{NO}_{x}$ emissions are roughly $25 \%$ higher than the EMEP (top-down) emissions. $\mathrm{NO}_{2}$ concentrations are slightly overestimated when using the Norwegian proxy data for traffic. Spatial correlation is improved with the use of the Norwegian proxy data for traffic compared to European emissions that use OSM data, from $r^{2}=0.6$ to 0.72 . It is worth noting that in the complete Norwegian calculation reported in Denby et al. (2020) using hourly calculations the spatial correlation is even higher at $r^{2}=0.78$, but the bias is less at $-5 \%$.

For $\mathrm{PM}_{2.5}$ biases are very similar for both the European and Norwegian proxy data sets when using either the European or Norwegian emissions. The spatial correlation, however, is significantly higher when using the Norwegian emissions both at grid level and after downscaling. There is significant improvement ( $r^{2}$ increases from 0.37 to 0.55 ) when changing European emissions to Norwegian emissions and changing the residential heating proxy from population (European proxy) to the MetVed model (Norwegian proxy). This indicates that improved spatial representation can be attained when both the gridded and the proxy data are consistent and more representative. However, little can be improved with downscaling when the initial gridded emissions are not well distributed, even with improved proxy data. Interestingly, we see the same result as reported in Sect. 4.2 that the spatial correlation is reduced when applying the European proxy data to the European emissions. These results indicate that significant improvements can still be obtained in the downscaling if improved emissions and emission proxies are implemented.

For $\mathrm{PM}_{10}$ both bias and spatial correlation are significantly improved with the implementation of the local emissions and proxies. This is to a large extent due to the improvement in the road dust emission contribution but also due to an improvement in the residential heating distribution. Spatial correlation is also significantly increased from $r^{2}=0.27$ to 0.49 .

\subsection{Sensitivity to the $\mathrm{NO}_{2}$ chemistry scheme}

Included in uEMEP are a number of simplified $\mathrm{NO}_{2}$ chemistry schemes used to derive downscaled $\mathrm{NO}_{2}$ concentrations from $\mathrm{NO}_{x}$ and $\mathrm{O}_{3}$ concentrations. In the results presented so far we have used the weighted travel time parcel method, as applied and described in Denby et al. (2020), with the additional use of the frequency distribution correction described in Sect. 2.4 ("Travel time" in Fig. 16). Two additional chemistry-based schemes and two experience-based schemes are also available. The two alternative chemistry schemes are the photostationary formulation ("Photostationary" in Fig. 16) and an alternative stationary formulation ("Stationary" in Fig. 16) that also allows for deviation from the photostationary state (Maiheu et al., 2017). The first empirical scheme is the Romberg scheme (Romberg et al., 1996) ("Romberg" in Fig. 16), also described in Denby et al. (2020), that directly converts $\mathrm{NO}_{x}$ to $\mathrm{NO}_{2}$ concentrations. The parameters for this equation have been updated by fitting to all available AIRBASE data for the year 2017. The other empirical formulation is the SRM scheme (Wesseling and van Velze, 2014) ("SRM" in Fig. 16) that is also based on a fit to measurement data but includes background $\mathrm{O}_{3}$ as one of the input parameters. The advantage of the two empirical fits is that they should convert $\mathrm{NO}_{x}$ to $\mathrm{NO}_{2}$ in a manner that is consistent with the observations and as such can be applied to annual mean concentrations directly without any correction for non-linearity. All methods are described in Sect. S1.

In Fig. 16 we provide the results of the sensitivity tests, showing bias and spatial correlation for both $\mathrm{NO}_{2}$ and $\mathrm{O}_{3}$. The three chemistry-based schemes give similar results, indicating that in all three cases the calculations are close to photostationary. The two empirical fits also give similar results, with the largest negative bias in $\mathrm{NO}_{2}$ given by the Romberg scheme with $-25 \%$. Since the Romberg scheme is specifically designed to reflect measurements, providing the correct $\mathrm{NO}_{2} / \mathrm{NO}_{x}$ ratio, it can be regarded as the closest to the measurements. The bias differences between chemistry schemes and the Romberg scheme indicate that chemistry schemes have higher concentrations of $\mathrm{NO}_{2}$ than the Romberg scheme, thus overestimating the $\mathrm{NO}_{2}$ contribution when applied to annual mean concentrations. This is partially due to the positive bias in the EMEP model $\mathrm{O}_{3}$ concentrations of $16 \%$, but this only accounts for around $4 \%$ of the 

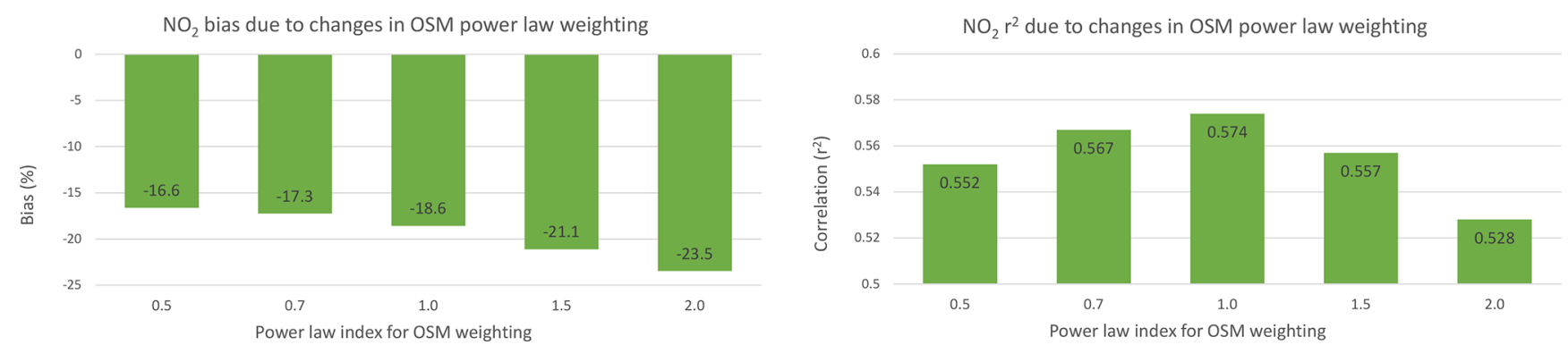

Figure 13. Change in bias and spatial correlation (coefficient of determination $r^{2}$ ) for $\mathrm{NO}_{2}$ as a result of changes in the power-law index applied to the OSM road traffic weighting. Lower power-law indices give more weight to minor roads, and higher power-law indices give more weight to major roads. The results are based on the European calculations, and all available AIRBASE stations are included.
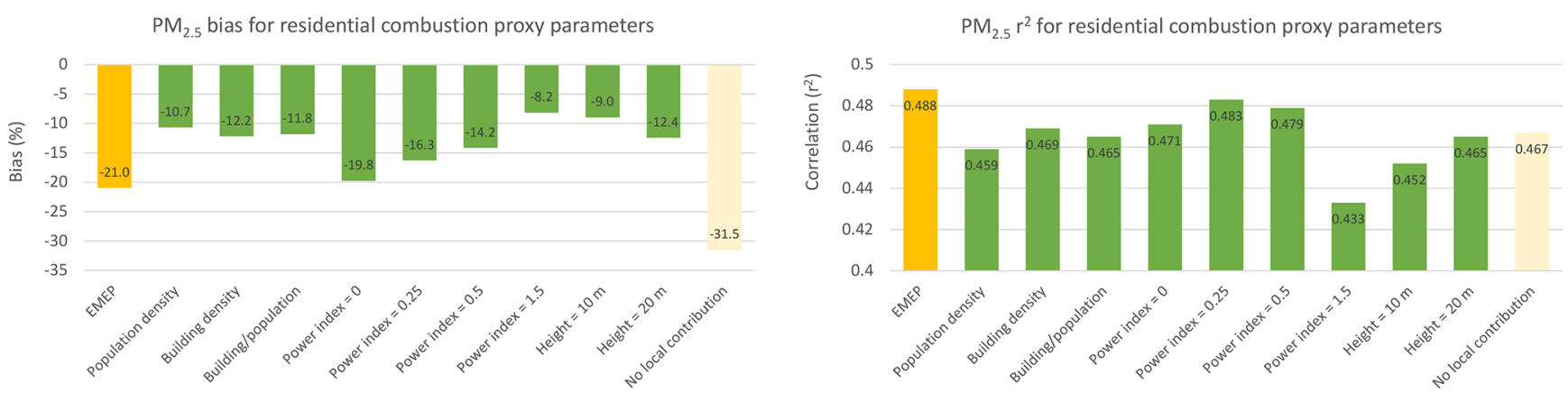

Figure 14. Change in bias and spatial correlation (coefficient of determination $r^{2}$ ) for $\mathrm{PM}_{2.5}$ as a result of changes in the residential combustion proxy. A lower power-law index gives less weight to the population redistribution, and a higher power-law indices give more weight. "Building/population" is the building density masked by population data. See text for details.

additional $\mathrm{NO}_{2}$. Included in Fig. 16 is the annual mean calculation without the frequency distribution correction ("Travel time (annual)"), showing a $10 \%$ difference in bias when compared to calculations that use this correction. Spatial correlation is also improved by using the frequency distribution methodology.

\section{Discussion}

Downscaling only applies to emissions within a limited region of $\pm 0.1^{\circ}$ surrounding each receptor sub-grid. Based on the uEMEP calculation, the local contributions to $\mathrm{NO}_{x}$ are significantly larger than for PM. The different source contributions at measurement sites are given in Table 2, and this shows that, on average in Europe, $58 \%$ of the $\mathrm{NO}_{x}$ contribution comes from traffic within this limited region. In contrast, only $19 \%$ of the $\mathrm{PM}_{2.5}$ is attributable to residential heating, the largest downscaled contribution, from inside this region.

$\mathrm{NO}_{2}$ is well modelled with high spatial correlation for many countries, but still with a significant negative bias of $-18 \%$. There is significant variation in bias between countries even though the methodology is consistently applied to all countries. This may be attributable to the various methods used for generation of the national emissions. Though the problem remains that uEMEP does not take into account dis- persion in street canyons, where a number of traffic site measurements are made, it is generally the case that the spatial representativeness of the UEMEP calculations is suitable for comparison with these measurements (Lefebvre et al., 2013). Variation in bias between countries is then no longer a case of a mismatch in resolution but most likely reflects bias in the national emissions. The uEMEP may be used to investigate this variability between countries further and to help harmonise future emission inventories across Europe.

There is a significant difference between the results achieved for the downscaling of PM compared to $\mathrm{NO}_{2} \cdot \mathrm{NO}_{2}$ is dominated by traffic emissions, and this is spatially well defined using OSM as a proxy. The largest contributor to PM in the downscaled sources is residential heating, with contributions of $19 \%$ and $16 \%$ for $\mathrm{PM}_{2.5}$ and $\mathrm{PM}_{10}$, respectively (Table 2). This is in line with other estimates of residential combustion in Europe. Thunis et al. (2017) calculated a contribution of $13 \%$ from residential combustion from primary $\mathrm{PM}_{2.5}$ averaged over 150 European cities without downscaling. Population is used as a downscaling proxy for the residential source, but it appears that this is not a good proxy for high-resolution emission redistribution. Though clearly residential heating emissions occur where people live there can be large variation from city to city and from urban to suburban to rural areas as heating practices vary significantly 

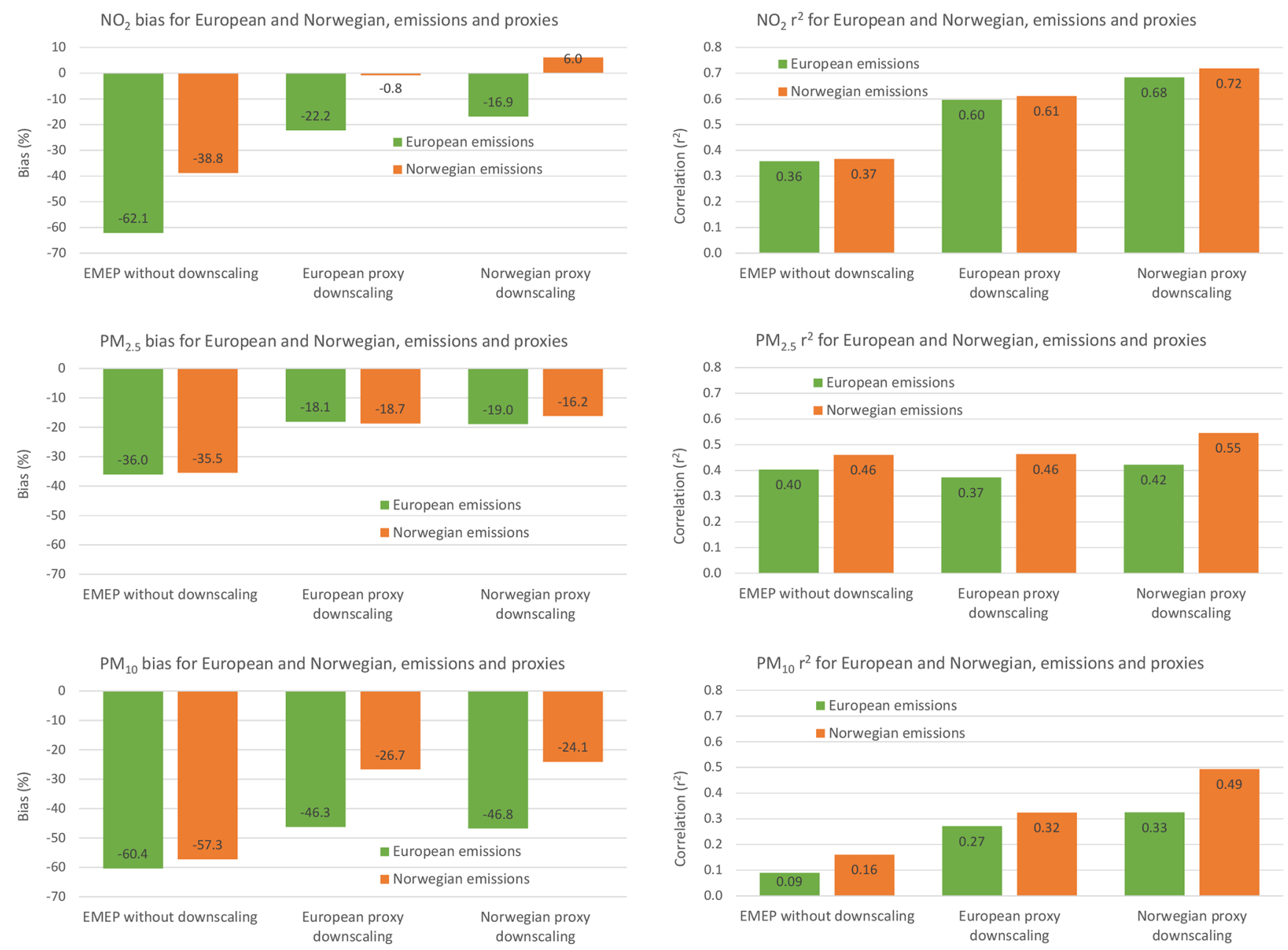

Figure 15. Change in bias and spatial correlation (coefficient of determination $r^{2}$ ) as a result of changes in Norwegian emission and emission proxy data for $\mathrm{NO}_{2}, \mathrm{PM}_{2.5}$, and $\mathrm{PM}_{10}$ calculations. "European emissions" represents the emissions used for all of Europe, and "Norwegian emissions" replaces these emissions for traffic and residential heating with alternative emissions used in the Norwegian air quality forecasting system. "European" and "Norwegian" proxy downscaling is explained in the text. Calculation year is 2017. The number of available stations is 41,36 , and 44 for $\mathrm{NO}_{2}, \mathrm{PM}_{2.5}$, and $\mathrm{PM}_{10}$, respectively.

Table 2. Source contribution to all air quality stations in Europe calculated with uEMEP. The uEMEP local contributions are from primary emissions within a region of $2 \times 2$ EMEP grids $\left( \pm 0.1^{\circ}\right)$ in both latitude and longitude. Non-local EMEP model contributions are all emissions from outside this region for the downscaled sources, as well as all other primary and precursor emission sources from within this region that are not downscaled.

\begin{tabular}{lrrr}
\hline Source & $\begin{array}{r}\mathrm{NO}_{x} \\
\left(\mathrm{~g} \mathrm{~m}^{-3}\right)\end{array}$ & $\begin{array}{r}\mathrm{PM}_{2.5} \\
\left(\mu \mathrm{g} \mathrm{m}^{-3}\right)\end{array}$ & $\begin{array}{r}\mathrm{PM}_{10} \\
\left(\mu \mathrm{g} \mathrm{m}^{-3}\right)\end{array}$ \\
\hline Traffic (GNFR6) & $13.9(58 \%)$ & $0.71(6 \%)$ & $1.1(7 \%)$ \\
Residential heating (GNFR3) & $1.8(8 \%)$ & $2.2(19 \%)$ & $2.6(16 \%)$ \\
Shipping (GNFR7) & $0.30(1 \%)$ & $0.01(0.1 \%)$ & $0.01(0.1 \%)$ \\
Non-local EMEP & $7.9(33 \%)$ & $8.4(75 \%)$ & $12.3(77 \%)$ \\
\hline Total & $23.9(100 \%)$ & $11.3(100 \%)$ & $16.0(100 \%)$ \\
\hline
\end{tabular}



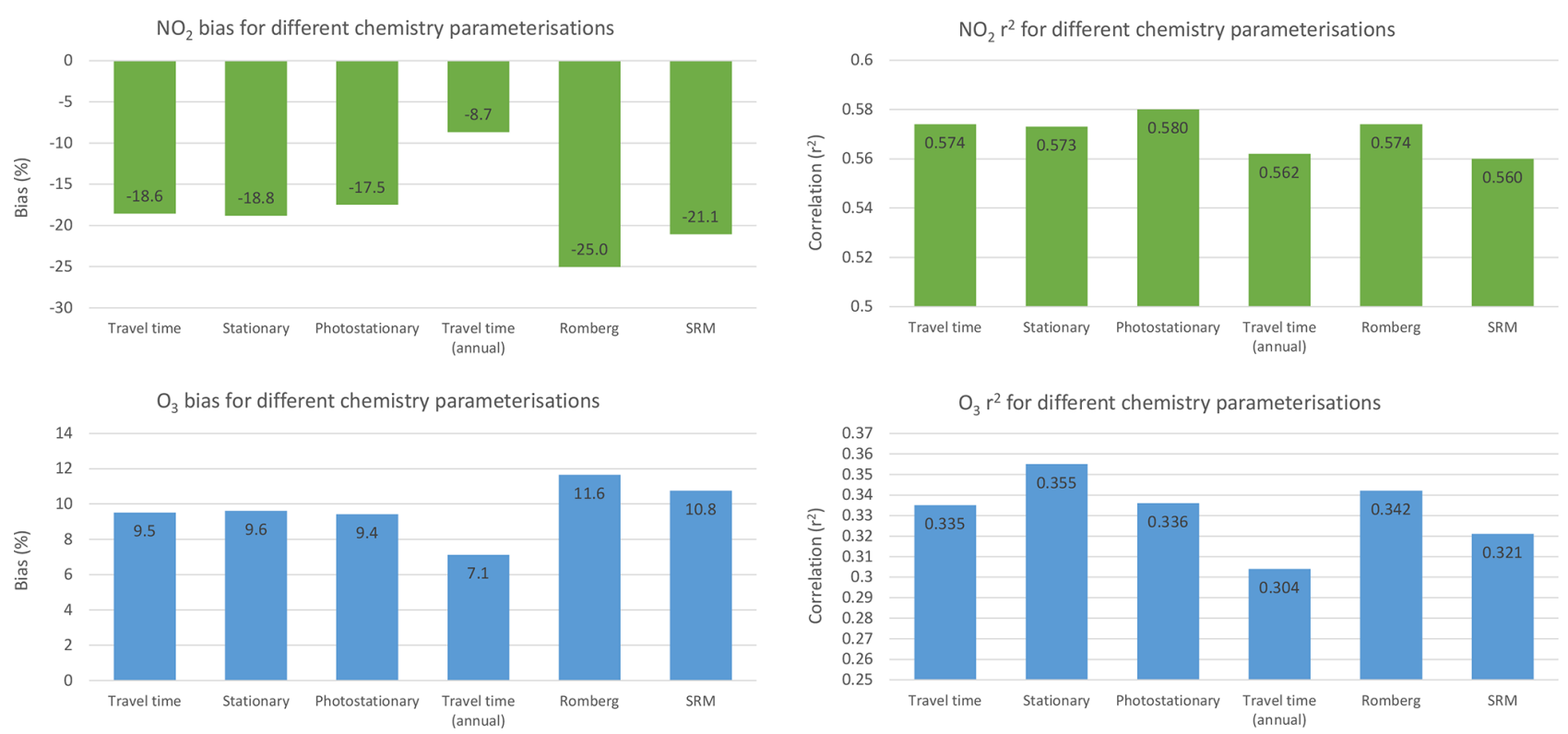

Figure 16. Change in bias and spatial correlation (coefficient of determination $r^{2}$ ) for $\mathrm{NO}_{2}$ and $\mathrm{O}_{3}$ with implementation of six different versions of the chemistry schemes. See text for details.

depending on housing type and on availability of alternative heating sources. To some extent this has been taken into account in the emission inventory at $0.1^{\circ}$, but the emission proxy used in uEMEP is likely not consistent with the EMEP emission inventory.

The Norwegian sensitivity tests show that when consistent emissions and emission proxies are used spatial correlation can be significantly improved. For the application of uEMEP in Europe this was not the case since each country has its own methodology for calculating gridded EMEP emissions that may or may not make use of the downscaling proxies applied in uEMEP. A more consistent approach, as applied in Norway, would be to use the same spatial redistribution proxies in both the gridded EMEP emissions and the downscaling proxies. This would require additional interaction and cooperation between emission inventory developers and air quality modellers.

It is worth noting that no selection of the AIRBASE monitoring data was carried out. All available stations with more than $75 \%$ coverage were used. This includes mountain stations, all traffic stations, and industrially sited stations. In comparisons with the EMEP model these types of sites are often removed. All stations were also assumed to be sited at $3 \mathrm{~m}$ above the surface. It is quite possible that different results would be obtained if a selection of stations was carried out. This will be assessed at a later time.

\section{Conclusions}

Downscaling of annual mean concentrations from the EMEP model have been carried out for $\mathrm{NO}_{2}, \mathrm{PM}_{2.5}, \mathrm{PM}_{10}$, and $\mathrm{O}_{3}$ using the uEMEP model. Downscaling redistributes EMEP gridded emission data using suitable proxy data to highresolution sub-grids and then calculates the sub-grid concentrations using a Gaussian dispersion model. These are then recombined with the EMEP model concentrations in a consistent way that avoids double counting of the emissions. Maps for all of Europe have been produced at a resolution of $100 \mathrm{~m}$, and concentrations at all AIRBASE measurement sites have been calculated at $25 \mathrm{~m}$.

The results for $\mathrm{NO}_{2}$ show significant improvement with a doubling of spatial correlation for most countries and a significant reduction in negative bias. For $\mathrm{NO}_{2}$ the downscaling works very well, which is due to the fact that $\mathrm{NO}_{x}$ emissions are mainly attributable to traffic, and these emissions are well defined spatially with the proxy data used. $\mathrm{O}_{3}$ concentrations are decreased due to higher $\mathrm{NO}_{x}$ concentrations. Both concentrations and spatial correlations of $\mathrm{O}_{3}$ are better simulated with uEMEP.

Neither $\mathrm{PM}_{2.5}$ nor $\mathrm{PM}_{10}$ shows any improvement in spatial correlation with the downscaling, though the negative bias in PM concentrations is improved. The spatial distribution of PM emissions can be improved, as demonstrated for Norway, with more accurate proxy data, but emissions of PM remain difficult to quantify properly at high resolutions and will require further effort. One way forward is to harmonise the proxies used for both the EMEP gridded emissions and the uEMEP downscaling. This has been shown to improve results in Norway.

Downscaling can provide additional information concerning the contributions of local sources. This may be combined with the EMEP model source-receptor calculations to pro- 
vide a more complete picture of local and long-transported contributions. The method can lead to a better assessment of local versus regional mitigation strategies to improve air quality in Europe at high resolution. It also shows good potential to be used to improve exposure estimates.

Code and data availability. The uEMEP_v6 model used in this study is archived on Zenodo (https://doi.org/10.5281/zenodo.4923185, Denby, 2021a), as are MATLAB scripts for visualisation of European uEMEP calculations (https://doi.org/10.5281/zenodo.4923224, Denby, 2021b). The latest development of uEMEP can be downloaded at https://github.com/metno/uEMEP (last access: 11 January 2022, Norwegian Meteorological Institute, 2022a). The EMEP model version rv4.36 used in this study can be found at https://github.com/metno/emep-ctm (last access: 11 January 2022, Norwegian Meteorological Institute, 2022b). The configuration file of the EMEP model is archived at https://doi.org/10.5281/zenodo.5648145, Mu, 2021). Other model input files can be shared upon request, including the meteorological input files that are generated by the IFS model version Cycle 40r1 (ECMWF-IFS cy40r1).

Supplement. The supplement related to this article is available online at: https://doi.org/10.5194/gmd-15-449-2022-supplement.

Author contributions. QM carried out the EMEP model calculations, processed the raw proxy data as input files for uEMEP, and was responsible for the text. BRD developed the downscaling method of Europe in uEMEP and contributed to the text and figures. EGW provided the frequency distribution correction and contributed to the text. HF internally reviewed and contributed to the text.

Competing interests. The contact author has declared that neither they nor their co-authors have any competing interests.

Disclaimer. Publisher's note: Copernicus Publications remains neutral with regard to jurisdictional claims in published maps and institutional affiliations.

Acknowledgements. The uEMEP development was supported by the Norwegian Public Roads Administration (Statens Vegvesen), the Norwegian Environment Agency (Miljødirektoratet), and the Ministry of Climate and Environment (Klima- og miljødepartementet). We thank David Simpson for a nice internal review. Map data are copyrighted by OpenStreetMap contributors and available from https://www.openstreetmap.org (last access: 11 January 2022).
Financial support. This research has been supported by the Research Council of Norway (Norges Forskningsråd, grant no. 267734).

Review statement. This paper was edited by David Topping and reviewed by two anonymous referees.

\section{References}

Denby, B. R.: metno/uEMEP: uEMEPv6 (6.0), Zenodo [code], https://doi.org/10.5281/zenodo.4923185, 2021a.

Denby, B. R.: uEMEP matlab plotting scripts for visualisation of European uEMEP calculations, Zenodo [code], https://doi.org/10.5281/zenodo.4923224, 2021 b.

Denby, B. and Wind, P.: Development of a downscaling methodology for urban applications (uEMEP), in: Transboundary particulate matter, photo-oxidants, acidifying and eutrophying components, The Norwegian Meteorological Institute, Oslo, Norway, EMEP Status Report 1/2016, 75-88, 2016.

Denby, B., Sundvor, I., Johansson, C., Pirjola, L., Ketzel, M., Norman, M., Kupiainen, K., Gustafsson, M., Blomqvist, G., Kauhaniemi, M., and Omstedt, G.: A coupled road dust and surface moisture model to predict non-exhaust road traffic induced particle emissions (NORTRIP). Part 2: Surface moisture and salt impact modelling, Atmos. Environ., 81, 485-503, https://doi.org/10.1016/j.atmosenv.2013.09.003, $2013 \mathrm{a}$.

Denby, B., Sundvor, I., Johansson, C., Pirjola, L., Ketzel, M., Norman, M., Kupiainen, K., Gustafsson, M., Blomqvist, G., and Omstedt, G.: A coupled road dust and surface moisture model to predict non-exhaust road traffic induced particle emissions (NORTRIP). Part 1: Road dust loading and suspension modelling, Atmos. Environ., 77, 283-300, https://doi.org/10.1016/j.atmosenv.2013.04.069, $2013 \mathrm{~b}$.

Denby, B. R., Gauss, M., Wind, P., Mu, Q., Grøtting Wærsted, E., Fagerli, H., Valdebenito, A., and Klein, H.: Description of the uEMEP_v5 downscaling approach for the EMEP MSC-W chemistry transport model, Geosci. Model Dev., 13, 6303-6323, https://doi.org/10.5194/gmd-13-6303-2020, 2020.

Denier van der Gon, H., Kuenen, J., and Visschedijk, A.: The TNO CAMS inventories, and alternative (Ref2) emissions for residential wood combustion, in: Transboundary particulate matter, photo-oxidants, acidifying and eutrophying components, The Norwegian Meteorological Institute, Oslo, Norway, EMEP Status Report 1/2020, 77-82, available at: https://www.emep.int/ (last access: 11 January 2022), 2020.

EMEP Status Report 1/2017: Transboundary particulate matter, photo-oxidants, acidifying and eutrophying components, EMEP MSC-W \& CCC \& CEIP, Norwegian Meteorological Institute (EMEP/MSC-W), Oslo, Norway, 2017.

EMEP/MSC-W, EMEP/CCC, EMEP/CEIP, CCE/UBA, Chalmers/SMHI, TNO, EMPA, and DWD: EMEP Status Report 2020, Tech. rep., chap. 2.3, 21-22, 2020.

European Environment Agency: Air Quality e-Reporting products on EEA data service, available at: https://www.eea.europa. eu/data-and-maps/data/aqereporting- 8 (last access: 11 January 2022), 2018. 
Fagerli, H., Simpson, D., Wind, P., Tsyro, S., Nyiri, A., and Klein, H.: Condensable organics: model evaluation and source receptor matrices for 2018, in: Transboundary particulate matter, photooxidants, acidifying and eutrophying components, The Norwegian Meteorological Institute, Oslo, Norway, EMEP Status Report 1/2020, 83-97, available at: https://www.emep.int/ (last access: 11 January 2022), 2020.

Grythe, H., Lopez-Aparicio, S., Vogt, M., Vo Thanh, D., Hak, C., Halse, A. K., Hamer, P., and Sousa Santos, G.: The MetVed model: development and evaluation of emissions from residential wood combustion at high spatio-temporal resolution in Norway, Atmos. Chem. Phys., 19, 10217-10237, https://doi.org/10.5194/acp-19-10217-2019, 2019.

Jonson, J., Kylling, A., Berntsen, T., Isaksen, I., Zerefos, C., and Kourtidis, K.: Chemical effects of UV fluctuations inferred from total ozone and tropospheric aerosol variations, J. Geophys. Res., 105, 14561-14574, 2000.

Kim, Y., Wu, Y., Seigneur, C., and Roustan, Y.: Multi-scale modeling of urban air pollution: development and application of a Street-in-Grid model (v1.0) by coupling MUNICH (v1.0) and Polair3D (v1.8.1), Geosci. Model Dev., 11, 611-629, https://doi.org/10.5194/gmd-11-611-2018, 2018.

Kystverket: AIS global shipping emission data, directly provided by Kystverket to MET Norway, available at: https://www. kystverket.no/en (last access: 11 January 2022), 2020.

Lefebvre, W., Van Poppel, M., Maiheu, B., Janssen, S., and Dons, E.: Evaluation of the RIO-IFDM-street canyon model chain, Atmos. Environ., 77, 325-337, https://doi.org/10.1016/j.atmosenv.2013.05.026, 2013.

Maiheu, B., Williams, M. L., Walton, H. A., Janssen, S., Blyth, L., Velderman, N., Lefebvre, W., Vanhulzel, M., and Beevers, S. D.: Improved Methodologies for NO2 Exposure Assessment in the EU, Vito Report no. 2017/RMA/R/1250, available at: https://ec. europa.eu/environment/air/publications/models.htm (last access: 11 January 2022), 2017.

Menut, L., Bessagnet, B., Khvorostyanov, D., Beekmann, M., Blond, N., Colette, A., Coll, I., Curci, G., Foret, G., Hodzic, A., Mailler, S., Meleux, F., Monge, J.-L., Pison, I., Siour, G., Turquety, S., Valari, M., Vautard, R., and Vivanco, M. G.: CHIMERE 2013: a model for regional atmospheric composition modelling, Geosci. Model Dev., 6, 981-1028, https://doi.org/10.5194/gmd-6-981-2013, 2013.

Miljodirektoratet: Air Quality Expert Service, available at: https:// www.miljodirektoratet.no/ (last access: 11 January 2022), 2020a.

Miljodirektoratet: Norwegian Air Quality Forecasting System, available at: https://luftkvalitet.miljodirektoratet.no/ (last access: 11 January 2022), 2020b.

Mu, Q.: EMEP model configuration file for the study "Downscaling of air pollutants in Europe using uEMEP_v6", Zenodo [data set], https://doi.org/10.5281/zenodo.5648145, 2021.

Norwegian Meteorological Institute (MET Norway): metno/uEMEP, MET Norway [code], available at: https://github.com/metno/uEMEP, last access: 11 January 2022a.

Norwegian Meteorological Institute (MET Norway): metno/emepctm, MET Norway [code], available at: https://github.com/ metno/emep-ctm, last access: 11 January 2022b.
OpenStreetMap contributors: Planet dump retrieved from https: //planet.osm.org/, available at: https://www.openstreetmap.org (last access: 11 January 2022), 2020.

Pinterits, M., Ullrich, B., Mareckova, K., Wankmüller, R., and Anys, M.: Inventory review 2020. Review of emission data reported under the LRTAP Convention and NEC Directive. Stage 1 and 2 review, Status of gridded and LPS data, EMEP/CEIP Technical Report 4/2020, CEIP/EEA Vienna, 2020.

Romberg, E., Bosinger, R., Lohmeyer, A., Ruhnke, R., and Röth, E.: NO-NO2-Umwandlung für die Anwendung bei Immissionsprognosen für Kfz-Abgase, Gefahrstoffe, Reinhaltung der Luft, 56, 215-218, 1996.

Schiavina, M., Freire, S., and MacManus, K.: GHS population grid multitemporal (1975, 1990, 2000, 2015) R2019A, European Commission, Joint Research Centre (JRC) [data set], https://doi.org/10.2905/42E8BE89-54FF-464E-BE7BBF9E64DA5218, 2019.

Simpson, D., Benedictow, A., Berge, H., Bergström, R., Emberson, L. D., Fagerli, H., Flechard, C. R., Hayman, G. D., Gauss, M., Jonson, J. E., Jenkin, M. E., Nyíri, A., Richter, C., Semeena, V. S., Tsyro, S., Tuovinen, J.-P., Valdebenito, Á., and Wind, P.: The EMEP MSC-W chemical transport model - technical description, Atmos. Chem. Phys., 12, 7825-7865, https://doi.org/10.5194/acp-12-7825-2012, 2012.

Simpson, D., Bergström, R., and Wind, P.: Updates to the EMEP MSC-W model, 2019-2020, in: Transboundary particulate matter, photo-oxidants, acidifying and eutrophying components, EMEP Status Report 1/2020, The Norwegian Meteorological Institute, Oslo, Norway, 2020.

Sofiev, M., Vira, J., Kouznetsov, R., Prank, M., Soares, J., and Genikhovich, E.: Construction of the SILAM Eulerian atmospheric dispersion model based on the advection algorithm of Michael Galperin, Geosci. Model Dev., 8, 3497-3522, https://doi.org/10.5194/gmd-8-3497-2015, 2015.

Stocker, J., Hood, C., Carruthers, D., and McHugh, C.: ADMSUrban: developments in modelling dispersion from the city scale to the local scale, Int. J. Environ. Pollut., 50, 308-316, https://doi.org/10.1504/IJEP.2012.051202, 2012.

Tarrasón, L., Hak, C., Soares, J., Røen, H., Ødegård, R., Green, J., and Marsteen, L.: Assessing the spatial representativeness of air quality sampling points: Application of siting criteria and sampling point classification - Task 3 report, Ricardo Group, Ref: ED 11492 - Final Task 3, 2021.

Thunis, P., Degraeuwe, B., Peduzzi, E., Pisoni, E., Trombetti, M., Vignati, E., Wilson, J., Belis, C., and Pernigotti, D.: Urban PM2.5 Atlas: Air Quality in European cities, EUR 28804 EN, Publications Office of the European Union, Luxembourg, 2017.

Wesseling, J. and van Velze, K.: Technische beschrijving van standaardrekenmethode 2 (SRM-2) voor luchtkwaliteitsberekeningen, RIVM Briefrapport 2014-0109, available at: https://core.ac. uk/download/pdf/58774365.pdf (last access: 11 January 2022), 2014.

Wind, P., Rolstad Denby, B., and Gauss, M.: Local fractions - a method for the calculation of local source contributions to air pollution, illustrated by examples using the EMEP MSC-W model (rv4_33), Geosci. Model Dev., 13, 1623-1634, https://doi.org/10.5194/gmd-13-1623-2020, 2020. 